\title{
In vitro follicle culture in the context of IVF
}

\author{
Anamaria C Herta, Francesca Lolicato and Johan E J Smitz \\ Follicle Biology Laboratory, Vrije Universiteit Brussel, Brussels, Belgium \\ Correspondence should be addressed to J E J Smitz; Email: Johan.Smitz@uzbrussel.be
}

This paper is part of an Anniversary Issue celebrating 40 years of in vitro fertilization. The Guest Editor for this section was Professor Lord Robert Winston.

\begin{abstract}
The currently available assisted reproduction techniques for fertility preservation (i.e. in vitro maturation (IVM) and in vitro fertilization) are insufficient as stand-alone procedures as only few reproductive cells can be conserved with these techniques. Oocytes in primordial follicles are well suited to survive the cryopreservation procedure and of use as valuable starting material for fertilization, on the condition that these could be grown up to fully matured oocytes. Our understanding of the biological mechanisms directing primordial follicle activation has increased over the last years and this knowledge has paved the way toward clinical applications. New multistep in vitro systems are making use of purified precursor cells and extracellular matrix components and by applying bio-printing technologies, an adequate follicular niche can be built. IVM of human oocytes is clinically applied in patients with polycystic ovary/polycystic ovary syndrome; related knowhow could become useful for fertility preservation and for patients with maturation failure and follicle-stimulating hormone resistance. The expectations from the research on human ovarian tissue and immature oocytes cultures, in combination with the improved vitrification methods, are high as these technologies can offer realistic potential for fertility preservation.

Reproduction (2018) 156 F59-F73
\end{abstract}

\section{Introduction}

For several decades, researchers have been interested in culturing gametes to better understand the intricate processes regulating the genesis of mature oocytes within the complexity of the female gonad. The ovary contains at all times follicles in different stages of growth, which are most often in the process of becoming atretic as soon as they are visible by ultrasound. A reduction of the complexity in understanding the growth of follicles can be achieved by synchronizing and monitoring in vitro the cohort to be studied, by using the latest sophisticated biochemical and microscopy technologies. Not only has the scientific curiosity sparked research in folliculogenesis and oogenesis, there is currently an increasing amount of patients suffering from childhood cancers, who require gamete-devastating chemo- and/ or radio-therapies. These children, as well as adults in their reproductive years, could directly benefit from the possibility to culture gonadal tissue on the condition that it had been safely cryopreserved before chemotherapy. Ovarian tissue cryopreservation pioneered by several labs in Europe, USA and Australia has already proven to be a good option, as of today a pregnancy rate of nearly $30 \%$ has been reported after the use of autologous transplantation of the thawed tissue (Donnez \& Dolmans 2015). For some categories of patients, in whom auto-transplantation or oocyte/embryo freezing cannot be performed for practical or safety reasons (given the risk related to cancer relapse and exposure to high hormone doses in in vitro fertilization (IVF) cycles i.e.), the only alternative to restore ovarian function could be the in vitro culture approach that allows implanting back just the oocyte, after the cure of cancer. However, the 'in vitro road' promises to be long and tedious.

The class of follicles with the most interesting implication for oncofertility is early stage follicles. Primary and primordial follicles are the most abundant follicles present in females of all ages, and they possess intrinsic capability to withstand cytotoxic therapies and survive cryopreservation better than growing follicles (Laronda et al. 2014, Tagler et al. 2014). Although accomplished in mouse and lamb, (Muruvi et al. 2005, Hornick et al. 2013) isolation and culture of primordial follicles are difficult tasks in primates, due to the small size, the limited connections between the granulosa cells and oocytes and the complex extracellular matrix environment in which they develop (Woodruff \& Shea 2011). Moreover, finding a reliable and safe method for the synchronous activation of the primordial follicle class in vitro still remains challenging. Obtaining human ovarian tissue for the experimental setup of a reproducible follicle culture system is often complicated because the donor tissue is seldom of 
a good initial quality. Therefore, the valuable data obtained in different animal models by researchers in developmental biology and veterinary field have to be considered inspirational for the work in humans. In the last two decades, several groups could prove that early preantral/secondary follicles can be grown up to a stage where the oocyte can re-initiate meiosis, although still at a low final yield, in isolated follicle culture systems in mice (Cortvrindt \& Smitz 2001, Xu et al. 2006, 2009a, Hornick et al. 2013), large domestic animals (Songsasen et al. 2011, Silva et al. 2015), non-human primates (Xu et al. 2009b, 2010, 2011a,b, 2013, 2017) and in human (Telfer et al. 2008, Xu et al. 2009a, Laronda et al. 2014, Xiao et al. 2015, Yin et al. 2016, Abir et al. 2017). More sophisticated in vitro systems are being designed using the most recent knowledge from the omics, bio-printing technologies and microfluidics. Integration of these technologies should provide us with additional tools to better reproduce the follicular niche. A more optimistic message can be given for the in vitro maturation (IVM) of human oocytes, where cumulus oocyte complexes (COCs) are retrieved from small $(2-12 \mathrm{~mm})$ antral follicles. 'IVM' of ovarian oocytes from mouse, sheep, cow, pig, rhesus monkey and human was pioneered and successfully achieved in 1965 by the physiologist, Nobel Prize Winner 2010, Sir Robert Edwards (Edwards 1965a). Oocyte IVM, largely employed in animal breeding, can represent a potential alternative to follicle culture for cancer patients and a valid assisted reproductive technique for women unable to receive or access ovarian stimulation treatment, due to ovarian hypersensitivity risk, elevated cost or other social reasons. R G Edwards had the capacity to anticipate potential applications and benefits of IVM, as documented in his historical publications (Edwards 1965a,b). So far, IVM has been clinically applied in patients with polycystic ovary (PCO)/polycystic ovary syndrome (PCOS), but other indications can now be surely added, including fertility preservation, oocyte maturation failure and folliclestimulating hormone (FSH) resistance. Increased knowledge obtained only in the last decade on how the meiotic arrest and progression in the antral follicle is regulated has inspired major ways for improvement of culture methods. This review summarizes the work of several ovarian follicular biology laboratories and proposes a selection of the most significant studies addressing the in vitro follicle culture challenges and potential applications within human IVF. Some of the most recent advances of human IVM are also discussed. The review of these data increases our understanding of the mechanisms involved in oocyte's growth and final maturation and could suggest the refinements that have still to be made to further optimize the in vitro culture systems in view of fertilization and embryo culture in human.

\section{Proof-of-principle studies on early in vitro folliculogenesis using animal models}

Eppig and $\mathrm{O}^{\prime}$ Brien pioneered in vitro follicle culture about two decades ago and obtained the first live birth in the mouse model from in vitro-grown primordial follicles (Eppig \& O'Brien 1996). By making use of a 2-step culture system, individual follicles obtained by enzymatic dissection of whole neonatal ovary, were grown up to metaphase II oocyte. (Eppig \& O'Brien 1996). This in vitro production system was subsequently perfected in 2003 and led to the generation of a mouse colony, showing the reproducibility of primordial follicle culture in this model and eliminating the initial skepticism that in vitro culture would result in abnormal live offspring (O'Brien et al. 2003). The achievement of normal progeny from the culture of early stage oocytes was taken further when Japanese biologists described an inventive method to obtain live births and healthy pups starting from primordial germ cells (PGCs) (Morohaku et al. 2016), and more recently from IPS (induced pluripotent stem) cells following in vitro generation of the entire oogenesis cycle (Hikabe et al. 2016). These very complex and time-consuming experiments not only inspired the work in other species, but fundamentally proved that earliest stages of oocytes, even before PGC colonize the genital ridge, can represent a novel source of female gametes.

Large animal models as bovine, ovine, caprine, porcine and non-human primates such as rhesus macaque (Macaca mulatta), baboon (Papio anubis) and cynomolgus (Macaca fascicularis), have also been used to investigate the mechanism(s) behind follicle activation and generation of fertilizable oocytes. The whole organ culture approach successfully used in rodents was replaced by ovarian cortical strips culture (Hovatta et al. 1997, 1999). In most large mammals, follicles form during fetal life; hence, the strategy to use primordial follicles collected during the last trimester of gestation from baboon and bovine (Wandji et al. 1996, 1997) seemed appropriate. It was observed that culturing ovarian cortex from fetal baboon and fetal or adult bovine in serum-free medium supplemented with Insulin-Transferrin-Selenium (ITS), induced a massive activation of primordial follicles already after 2 days (Wandji et al. 1996, 1997). This uncontrolled spontaneous growth of primordial follicles when cultured in vitro was intriguing and elicited several hypotheses. An initial hypothesis that the absence of ovarian medulla could be responsible for primordial follicle activation in bovine could not be proven. Using the bovine model, the involvement of TGFa in the regulation of primary follicle development was demonstrated (Derrar et al. 2000). Later, it was suggested that Insulin and Kit Ligand could also play a role as primordial follicle activators (Muruvi \& Fortune 2009). 
Using the caprine model, Silva et al. (2004) cultured ovarian cortex to study the potential role of FSH and epidermal growth factor (EGF) in the follicle activation process. Spontaneous activation nevertheless occurred during in vitro culture and FSH and EGF induced an increase in size of oocyte and follicle but had no effect on wholesale activation. (Silva et al. 2004). Overall, the data obtained by the large mammals models were pivotal to show that in vitro follicular activation could be successfully achieved, despite the majority of activated follicles could not progress in a correctly differentiated manner or survive. On the other hand, several studies demonstrated that preantral follicle culture could lead to the production of embryos in several species: ovine (Arunakumari et al. 2010), caprine (Magalhães et al. 2011), porcine (Wu et al. 2001), bovine (Gupta et al. 2008), clearly indicating that follicle culture success strongly correlates with the stage of follicle and the size of oocyte at the beginning of the culture.

Finally, a different approach in follicle culture, represented by a 3D alginate encapsulation culture system capable to support in vitro follicle growth from secondary to the antral stage, was described in rhesus macaque (Xu et al. 2010, 2011a). Interestingly, the in vitro-grown oocytes could re-initiate meiosis, but their developmental capacity remained suboptimal, as proved after in vitro insemination by ICSI (Xu et al. 2010, 2011a). Similar results were also obtained in the same animal model, starting from the primary follicle stage (Xu et al. 2013).

\section{Significant progress made in the human model}

Relevant insights in follicle activation mechanisms were also obtained from research in the human model. Pioneering studies took inspiration from the complex structural organization of the ovary and suggested that its dynamic environment and the availability of nutrients, hormones and growth factors could play a major role in primordial follicle activation and growth. Basing their work on this assumption, Picton and Gosden adopted the strategy to grow early follicles in situ in cortical slices, to resemble the ovary in vivo, instead of isolating follicles for in vitro culture (Picton et al. 1999). This study suggested that the activation of human primordial follicles was not gonadotropin dependent, as was later confirmed in bovine (Silva et al. 2004) but rather supported by the ovarian cellular environment. In a similar approach, ovarian cortical tissue, donated by 20 women following gynecological laparoscopies, was first cultured in Matrigel (extracellular matrix), to initiate the growth of the primordial and primary follicles and then divided into two parts to either be cultured further as slices or used for enzymatic or mechanical partial isolation of the follicles (Hovatta et al. 1999). This study confirmed that the most appropriate method to culture human follicles was non-isolated, but within small tissue slices. Overall, these data showed the importance to tailor the culture strategies for in vitro growth of human follicles to the size of follicle; therefore, multistep culture systems to support each of the specific stages were developed (Telfer et al. 2008, Smitz et al. 2010, Telfer \& Mclaughlin 2012, Telfer \& Zelinski 2013). The aims of the multistep approach were to sustain homogenous primordial follicle activation and initiation of early follicular growth, support the growth and differentiation of early preantral to antral stage and provide the right maturation conditions of COCs. In 2008, using a twostep culture system without serum and matrix, Telfer et al. (2008) showed that human primordial follicles undergo activation and initiate growth within mechanically loosened cortical pieces, developing to multilaminar preantral (secondary) stages after only 6 days of culture (Telfer et al. 2008). The effectiveness of the stepwise approach was recently reiterated by McLaughlin et al. (2018) reporting the 1 st mature human oocyte from a unilaminar follicle grown in a multistep culture system. In this study, human ovarian cortex strips were cultured in a serum-free system and multilaminar follicles were dissected and individually cultured in the presence of recombinant activin A, in non-attachment (3D) condition. COCs and adherent mural granulosa were also cultured in presence of $\mathrm{FSH}$ and activin and further matured in vitro, resulting in a metaphase II oocyte (McLaughlin et al. 2018).

In view of a potential applicability in fertility preservation treatments, both approaches of cortical strips and isolated preantral follicles were taken in consideration. The most challenging aspect of the in vitro follicle culture, the activation step, was further investigated by Li et al. (2010) who proposed a protocol, developed in the mouse model, for chemical activation of dormant human primordial follicles by using ovarian cortical fragments from cancer patients treated with the phosphatase and tensin homolog deleted on chromosome 10 (PTEN) inhibitor dipotassium bisperoxo (picolinato) oxovanadate $(\mathrm{V})$ dihydrate (bpV(pic)) (Li et al. 2010). Short-term in vitro activation of dormant ovarian follicles after stimulation of the phosphatidylinositol-4,5-bisphosphate 3-kinase (PI3K) protein kinase B (AKT) pathway and transplanted under the mouse kidney capsula led to the growth of a large amount of mature female germ cells. This method has been promptly translated into the clinical practice for fertility treatment of women with ovarian insufficiency (Kawamura et al. 2013).

A slightly different approach aimed at using ovarian tissue cortex pieces for isolation of preantral follicles, to further culture in vitro and transplant without the risk of reintroducing malignant cells (Dolmans et al. 2007). The protocol based on enzymatic digestion and gradient purification allowed the isolation of a large population of primordial follicles, with good viability and morphology (Dolmans et al. 2006). To increase 
the chances of success for patients in need of fertility preservation treatments, recent research focused on identifying alternative sources for gamete collection rather than the ovarian cortex. It was suggested that the ovarian medulla could also be considered a source of follicles for fertility restoration in oncology patients and a protocol for enzymatic (Liberase, collagenase, deoxiribonuclease) isolation of viable preantral follicles from the ovarian medulla was recently proposed. The culture outcomes of these follicles looked promising, as they reached antral stage and had steroidogenic activity and anti-Müllerian hormone (AMH) secretion measured in their spent medium (Yin et al. 2016). Further steps have been taken in the direction of in vitro differentiation of human germ cells: an in vitro culture system capable to support the differentiation of human embryonic stem cells into ovarian follicle-like cells (FLCs) has been successfully applied (Jung et al. 2017). This approach could offer future perspectives for fertility restoration in patients with distinct pathologies like ovarian dysgenesis (e.g.: Turner Syndrome).

\section{Critical points}

Although major steps have been taken over the last two decades, improvements and refinements are still needed before in vitro folliculogenesis can be considered for clinical use. After achieving activation and initial growth in the cortical culture systems, in large mammals, only a small fraction of the primary follicles showed progress to the secondary stage, using suitable factors to support follicular growth and differentiation (reviewed by Smitz et al. 2010 and De Vos et al. 2014). For the primate model extended culture periods (e.g.: 5 weeks) were required when starting-off from secondary follicles (Ting et al. 2015). In non-human primates and in humans, the best results with this approach were obtained using expandable matrixes in 3D systems. however, only a low number of oocytes was capable of resuming meiosis upon ovulation trigger (Xu et al. 2013, Ting et al. 2015). Overall, fertilization efficiency and developmental capacity of oocytes obtained from in vitro follicle culture is still extremely low, and no blastocyst production was achieved so far (Xu et al. 2010, 2011a,b, 2013). One of the reasons for the limited success of this technology can be found in the lack of more appropriate and physiological culture systems. Poor outcomes of early in vitro growth may indeed reflect suboptimal culture conditions. To this purpose, the supplementation of stage-specific growth factors may be crucial in maintaining physical interactions and preventing cellular stress, formation of reactive oxygen species, accumulation of waste compounds and so forth. Early preantral stages require more profound molecular and biochemical characterization to better define the environmental conditions able to support follicle growth up to the antral stage. The identification of one or more biomarkers that indicate the optimal time for ovulation trigger and fertilization (Sánchez et al. 2012) could represent a valuable tool for reproducing in vitro the grade of maturity of the oocyte embedded in the cultured follicle (e.g.: related to the arrest of transcription, nuclear maturity of the oocyte, etc.). Secondly, obtaining a synchronous activation of primordial follicles during tissue culture as seen in early work on both bovine and baboon (Wandji et al. 1996, 1997) as well as on human (Hovatta et al. 1997, 1999, Telfer et al. 2008) is a critical point for the success of this technique because of the specific needs of the follicles throughout their development from primary to early cavitary stages. The use of chemicals for in vitro activation followed by follicle culture might be a viable strategy only when the safety could be guaranteed. These pharmacologic manipulations might induce, besides a synchronous activation, other parallel metabolic effects in intracellular and intercellular processes. Preliminary work indicated that the inhibition of PTEN with dipotassium bisperoxo (5-hydroxypyridine-2-carboxyl) oxovanadate (bpV(HOpic)) initiated follicle growth and development to the secondary stage, but had a negative impact on the subsequent survival of isolated secondary follicles (McLaughlin et al. 2014).

Over the last few years, special efforts have been made to identify the role of the main hormones involved in regulating follicular growth in vivo, and how they modulate the current in vitro culture systems. In the rhesus macaque in vitro model, estradiol (E2) was identified as an essential factor with positive effects on follicle survival, growth, differentiation and oocyte health in a steroid-depleted milieu (Ting et al. 2015). AMH was shown to induce follicle growth and differentiation, oocyte maturation and steroid secretion in a matrix-free 3D culture system (Xu et al. 2017). In non-human primates, a dynamic exposure of secondary follicles to local secreted factors in the $3 \mathrm{D}$ alginate encapsulation system, followed by the inclusion of gonadotropins upon reaching the antral growth stage, showed to be the more physiological condition (Baba et al. 2017). Despite some mature oocytes have been obtained, their developmental competence remained low as no blastocyst formation in non-human primates and no live births after embryo transfer from IVG oocytes in large animals have been reported so far. A strategy to increase the quality of oocytes derived from longterm follicle culture could be obtained by introducing a 'capacitation' culture step preceding the final IVM stimulus. Making use of physiologic meiotic inhibitors as the C-type natriuretic peptide (CNP) (Zhang et al. 2010, Kawamura et al. 2011, Tsuji et al. 2012), the completion of the oocyte cytoplasmic maturation could be supported before polar body extrusion, leading to a higher developmental competence of these oocytes. Proof-of-concept studies using CNP within the IVM context starting from small- and middle-size antral 
follicles in both animal (Zhang et al. 2011, 2015a,b, Franciosi et al. 2014, Wei et al. 2015, Zhong et al. 2016, Romero et al. 2016) and human (Sánchez et al. 2017) models were effective and safe. Additional advances in the field could be achieved by identifying suitable biomarkers and crucial parameters for the biochemical monitoring of the in vitro follicle development process.

\section{Control of follicular activation and early growth}

In order to overcome some of the above mentioned limitations, extensive work has been performed during the last decade to elucidate the main signaling pathways underlying follicular activation and early growth. Primordial follicles, enclosing meiosis-arrested oocytes, remain dormant in the mammalian ovary for periods of time as long as 50 years in human (Faddy \& Gosden 1996). Only part of these will be activated and recruited in the growing pool to generate mature oocytes (Lass et al. 1997). The flattened granulosa cells, the somatic component of the primordial follicles, are essential for the survival of the resting oocyte. A characteristic sign indicating the recruitment of a primordial follicle into the growing pool is the change in shape of the granulosa cells from flat to cuboidal, followed by growth of the oocyte (Hirshfield, 1991). The activation of mammalian target of rapamycin complex 1 (mTORC1) - KIT LIGAND (KITL) signaling pathway in pre-granulosa cells (p-GCs) of primordial follicles triggers the awakening of dormant oocytes and follows through with the process of follicular activation via PI3K signaling in oocytes (Zhang et al. 2014) (Fig. 1). The mechanisms and most studied pathways regulating primordial follicle activation have been extensively reviewed (Adhikari \& Liu 2009, Sánchez \& Smitz 2012, Hsueh et al. 2015, Zhang \& Liu 2015) and are briefly summarized below.

\section{The PI3K/PTEN-Akt-mTORC1-S6K-rpS6 cascade}

One of the better described mechanisms involved in follicle activation is the PI3K-PTEN-AKT-FOXO3 pathway (Zhang \& Liu 2015). The PI3K signaling pathway comprises a chain of molecules (kinases, phosphatases and transcription factors) mediating important cellular processes like proliferation, apoptosis, survival, growth, migration and metabolic activity (Cantley 2002, Chalhoub \& Baker 2009) and acts on primordial follicle awakening via the oocyte (Reddy et al. 2005, 2008) (Fig. 1). The follicular activation mechanism involves the binding of KIT LIGAND to the tyrosine kinase receptor (c-KIT) on the oocyte, which leads to formation and activation of the PI3K complex. This further induces the activation and the nuclear translocation of AKT, that inhibits the activity of the transcriptional factor forkhead box O3 (FOXO3) responsible for keeping the oocyte in a dormant state (Reddy et al. 2009). PTEN acts as a negative regulator of PI3K (Simpson \& Parsons 2001,

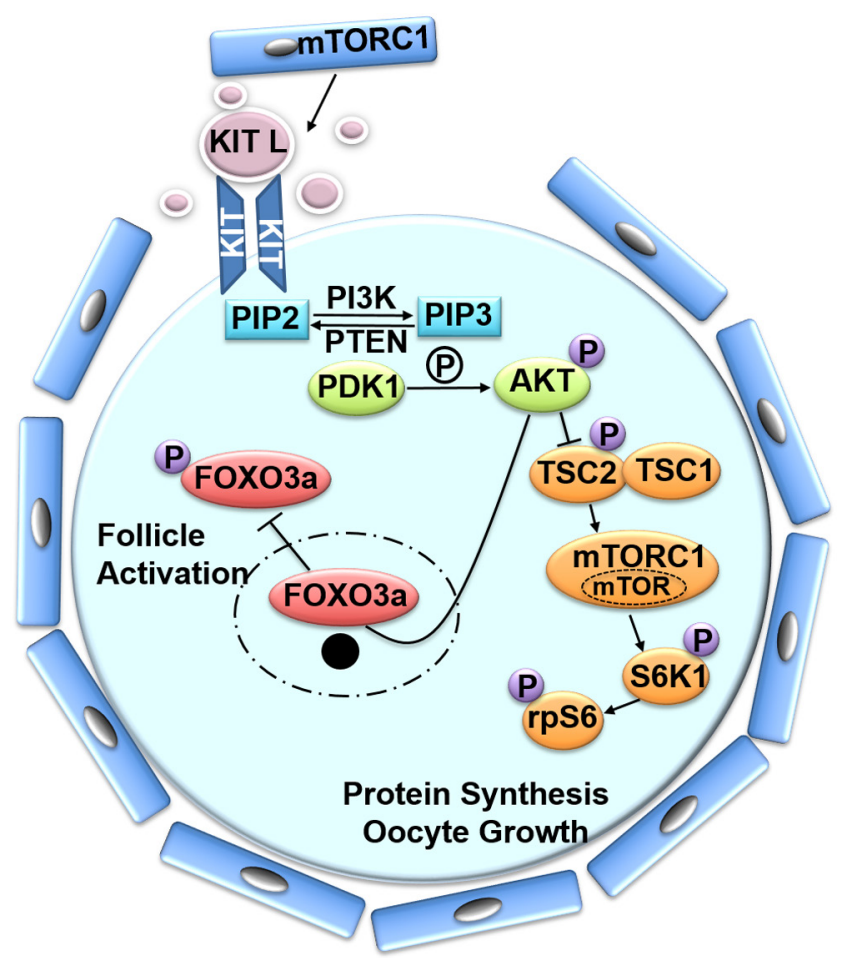

Figure 1 In vitro follicular activation and initial growth. Increased mTORC1 activity in p-GCs leads to upregulation of KITL production, which binds its KIT/tyrosine kinase receptor on the oocyte (Zhang et al. 2014) and triggers the formation and activation the PI3K complex. This stimulates conversion of PIP2 to PIP3, which in high levels drives the nuclear translocation and phosphorylation of AKT. Activated AKT triggers nuclear export and suppression of FOXO3 transcription factor activity, to promote follicle activation (Reddy et al. 2009; Sánchez \& Smitz, 2012). Deletion of the Foxo3a in female mice led to infertility due to global follicular activation (Castrillon 2003). PTEN acts as a regulator of PI3K by converting PIP3 into PIP2 (Simpson \& Parsons 2001, Cantley 2002). Its absence in the oocytes of a knock-out mouse upregulated PI3K activity, triggering premature activation and primary ovarian faliure as seen in the Foxo3-null mutant ovaries phenotype (John et al. 2008, Reddy et al. 2008). AKT induces cell growth and proliferation via mTOR activity. mTOR, a serine/threonine kinase, is the catalytic subunit of two distinct multiproteic complexes, mTORC1 and mTORC2. AKT induces activation of mTORC1 by inhibiting TSC2, a supressor of mTOR (Adhikari \& Liu 2010). mTORC1 regulates protein translation by phosphorylation of downstream molecules, 4E-BP1 (not shown) and S6K1, which triggers activation of rpS6 (Reddy et al. 2009). Deletion of mTOR-negative regulators TsC1 or Tsc2 from mouse oocytes, leads to primary ovarian failure (POF) due to increased mTORC1 activity in the oocytes triggering follicular over-activation and depletion (Adhikari et al. 2009, 2010). 4E-BP1, eukaryotic translation initiation factor $4 \mathrm{E}$ binding protein 1 ; $\mathrm{AKT}$, Protein Kinase B; FOXO3/FOXO3a, Forkhead box O3; KITL, KIT Ligand; mTOR, mammalian target of rapamycin; mTORC1, mTOR complex 1; mTORC2, mTOR complex 2; p-GCs, pre-granulosa cells; PI3K, Phosphatidylinositol-4,5-bisphosphate 3-kinase; PIP2,

Phosphatidylinositol (4,5)-bisphosphate; PIP3, phosphatidylinositol $(3,4,5)$ triphosphate; POF, primary ovarian failure; PTEN, phosphatase and tensin homolog deleted on chromosome 10; rpS6, ribosomal protein S6; S6K1, ribosomal protein S6 kinase beta-1; TSC1, Tuberous sclerosis protein 1 (tuberin); TSC2, Tuberous sclerosis protein 2 (hamartin). 
Cantley 2002). It has been shown that the modulation of PTEN activity via pharmacological inhibitors or PI3K activators during in vitro treatment of mouse ovaries and human cortical strips increased in vitro primordial follicle activation and led to successful growth of metaphase II oocytes, after xenotransplantation of the human ovarian tissue and hormonal stimulation (Li et al. 2010). Transplantation of the treated mouse grafts under the kidney capsules of ovariectomized mice, stimulated with gonadotropins, resulted in mature oocytes and healthy fertile pups after IVF (Li et al. 2010). Furthermore, AKT induces cell growth by activating the mammalian target of rapamycin (mTOR) (Adhikari \& Liu 2010). mTOR, a serine/threonine kinase forms two distinct multiproteic complexes, mTOR complex 1 (mTORC1) and 2 (mTORC2) (Laplante \& Sabatini 2012) involved in regulation of cell growth and proliferation (Adhikari \& Liu 2009; Fig. 1). Mouse work indicated that combined treatment of mTOR and AKT activators on prepubertal ovaries, followed by transplantation, generated a higher graft weight compared to AKT stimulators only treatment (Cheng et al. 2015). Sun et al. (2015) showed that mTOR activators (phosphatidic acid, propranolol) induced awakening of primordial follicles. When human ovarian cortex was briefly exposed to a combination of mTOR and $\mathrm{PI} 3 \mathrm{~K}$ pharmacological activators and cultured for 6 days, the yield in secondary stage follicles was significantly higher than when exposed to these stimulators individually (Sun et al. 2015).

\section{The Hippo signaling pathway: another pathway proven to regulate onset of follicle growth}

The Hippo signaling pathway plays a crucial role in growth regulation and normal organ size maintenance in all metazoan species (Pan 2007). This pathway was reviewed by Hsueh et al. (2015) in the context of ovarian physiology and physiopathology, describing its role in limiting early follicle development (Hsueh et al. 2015). Work in mouse from Kawamura et al. (2013) proved that fragmentation of ovaries promotes follicle growth. This effect was correlated with Hippo pathway disruption due to increased actin polymerization (conversion of G-Actin to F-Actin), which results in accumulation of yes-associated protein (YAP) in the nucleus. The transcription factor YAP upregulates the expression of $\mathrm{CCN}$ growth factors that modulate follicle growth and oocyte maturation (Kawamura et al. 2013) (Fig. 2).

\section{Potential application in the clinic}

The combination of the Hippo signaling disruption by tissue fragmentation and the pharmacological PI3K pathway stimulation in human ovarian cortical pieces with early preantral and secondary follicles, led to follicular growth up to pre-ovulatory stage within

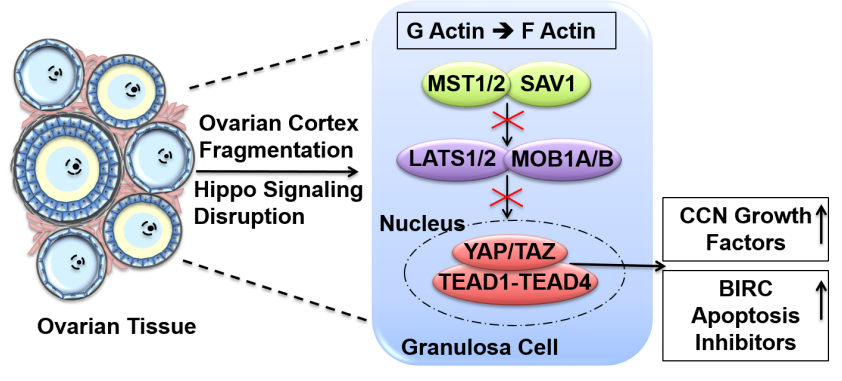

Figure 2 The Hippo pathway disruption (based on Hsueh et al., 2015). It plays an essential role in mainaining normal organ size and comprises a series of negative growth regulators that trigger phosphorylation and inactivation of the key signaling effectors, YAP/ TAZ. Actin polymerization (conversion of G-actin to F-actin) following tissue fragmentation is positively correlated with Hippo signaling disruption (Kawamura et al., 2013). A decline in YAP phosphorylation leads to increase in YAP nuclear levels. Nuclear YAP works together with TEAD transcriptional factors to upregulate the expression of BIRC apoptosis inhibitors and CCN growth factors (Pan 2007), which suport cell growth, survival and proliferation (Holbourn et al. 2008). BIRC apoptosis inhibitors: Baculoviral inhibitors of apoptosis repeat-containing proteins; $\mathrm{CCN}$ growth factors: acronym derrived from three of its members: CCN1 (cysteine-rich angiogenic protein 61 or), CCN2 (connective tissue growth factor) and CCN3 (nephroblastoma overexpressed); F-actin, filamentous; G-actin, globular actin; LATS1/2, mammalian homologs of Drosophila Warts; MOB1A/B, mammalian homologs of Drosophila Mats; MST1/2, mammalian; homologs of Drosophila Hippo; SAV1, homolog of Drosophila Salvador; TAZ, transcriptional coactivator with PDZbinding motif; TEAD transcriptional factors: Transcription factors containing the TEA/ATTS DNA binding domain; YAP, Yes-associated protein.

4 weeks of xenotransplantation in immune-deficient mice (Kawamura et al. 2013).

These results were further translated into the clinical set up for infertility treatment of patients with primary ovarian insufficiency (POI) by Kawamura et al. (2013). Thawed ovarian tissue was fragmented for Hippo pathway disruption to support follicular growth and further on, treated with pharmacological activators of the PI3K pathway to induce follicular awakening, followed by autologous transplantation. Within 2-3 weeks, follicular growth was detected and first live births were reported (Kawamura et al. 2013, Suzuki et al. 2015, Zhai et al. 2016) (Fig. 3).

\section{Future perspectives}

There are several follicle culture systems that have paved the way for growing oocytes as reviewed earlier (Smitz et al. 2010). Initial work to obtain oocyte growth within the cortical tissue strips seemed successful (Hovatta et al. 1997). However, passed this step, the tissue strip environment seemingly inhibited further growth. This led to the recommendation to isolate the growthinitiated follicles once these reached the secondary stage (Telfer et al. 2008). Further culture of isolated 


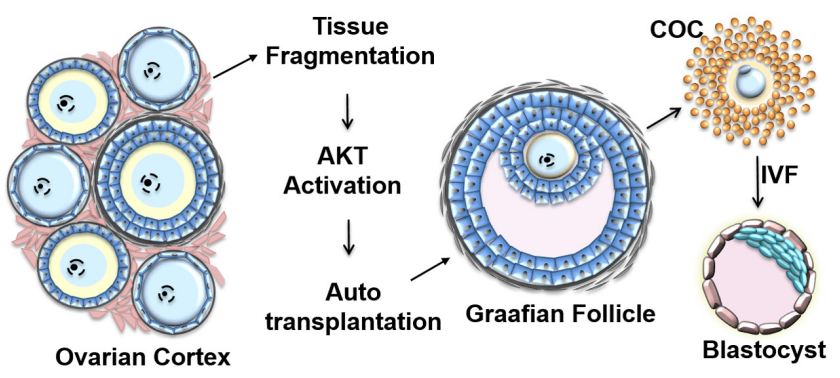

Figure $3 \mathrm{PI} 3 \mathrm{~K} / \mathrm{AKT} / \mathrm{mTOR}$ pathway and Hippo pathway disruption in ovarian failure patients. In vitro treatment of ovarian cortical pieces with PI3K activators/PTEN inhibitors, induces primordial follicle awakening via PI3K/AKT/mTOR signaling in the oocyte and supports follicle growth by upregulating AKT signaling in granulosa cells of preantral follicles (ccc). Ovarian fragmentation promotes follicular growth by inducing actin polymerization and Hippo signaling disruption. This downregulates YAP phosphorylation, followed by an increase in nuclear levels of YAP, and an elevated expression of CCN growth factors and BIRC apoptosis inhibitors (Kawamura et al. 2013). Tissue fragmentation and AKT stimulation followed by autotransplantation in primary ovarian faliure patients, resulted in preovulatory follicles in a few weeks (Kawamura et al. 2013, Suzuki et al. 2015, Zhai et al. 2016). This method generated mature oocytes for IVF-ET for some of the POI patients (Kawamura et al. 2013). After IVF-ET, clinical pregnancy and live births were reported (Kawamura et al. 2013, Suzuki et al. 2015, Zhai et al. 2016). AKT, Protein Kinase B; BIRC apoptosis inhibitors, Baculoviral Inhibitors of apoptosis Repeats-Containing proteins; CCN growth factors: the acronym derrived from three of its members: CCN1 (cysteine-rich angiogenic protein 61 or), CCN2 (connective tissue growth factor), and CCN3 (nephroblastoma overexpressed); ET, embryo transfer; IVF, in vitro fertilization; mTOR, mammalian target of rapamycin; PI3K, Phosphatidylinositol-4,5-bisphosphate 3-kinase; POI, primary ovarian insuficiency; PTEN, phosphatase and tensin homolog deleted on chromosome 10; YAP, Yes-associated protein.

secondary follicles was carried out in small inserts with or without extracellular matrix (ECM) or in plastic well plates (Smitz et al. 2010). The early preantral follicle culture is strongly influenced by the composition and architecture of its supporting tissue. This generated the need to develop extracellular matrixes and biomaterials that could imitate the ovarian physiologic milieu for optimal follicle development.

Several extracellular matrixes natural (collagen), synthetic (alginate) have been used in the attempt to keep the 3D structure during culture (West et al. 2007). The 3D culture techniques have advanced over the past few years, offering a wide range of options such as embedding cells in extracellular matrixes (natural and synthetic), printing 3D scaffolds, 3D bio printing of biocompatible materials and cells, decellularization/ recellularization of tissues and whole organs and also the use of more sophisticated microfluidics technology (Laronda et al. 2015, 2017). Choosing the promising way of follicle encapsulation in extracellular matrixes, imposes physiological requirements according to the class of follicles to be cultured. For example, primordial and primary follicles take great advantage from biomaterials with different physical properties (e.g.: stiffness, structure and composition, porosity) compared to secondary follicles. In a primate model, the early preantral follicles required a rigid environment for optimal survival and growth in vitro, corresponding better to the characteristics of the natural ovarian cortex areas containing these classes of follicles (Hornick et al. 2012). Over the last decade, bioengineering provided many alternatives for composing ECMs with different characteristics in order to meet the requirements of the cells to culture. Such an example is the 3D printing of biomaterials and cells into complex functional structures and tissues, as a result of pluridisciplinary work involving cell biology, medicine, physics alongside bioengineering and biomaterial science. (Murphy \& Atala 2014). The 3D bio printing has been applied in regenerative medicine, due to its great potential in in vitro manufacturing tissues and organs (Bajaj et al. 2014) aiming to eliminate the shortage of organs suitable for transplantation. A more physiological alternative is represented by the use of natural scaffolds obtained by separation of the extracellular matrix (ECM) from its residing cells (whole organ decellularization), which can preserve the original constitution and architecture of the tissue or organ (Gilpin \& Yang 2017). Laronda et al. (2015), used this technique and successfully decellularized a mouse ovary and then re-cellularized it with granulosa, theca and germ cells. These transplanted ovaries induced puberty in sterilized mice (Laronda et al. 2015). This research is now continued by using 3D printed scaffolds, which would support the maintenance of the spherical follicle structure and of the gamete-somatic cells connections, for oocyte growth and maturation (Laronda et al. 2017). The 3D print microporous hydrogel scaffold was designed to meet the requirements of follicle growth and expansion with defined rigidity, advancing angles (impacting on survival rates) and porosity (allowing vascularization and ovulation). Following transplantation to sterilized mice of the follicle-seeded scaffolds, the ovarian function was fully regained and fertility restoration was proved by live birth of healthy pups after natural mating (Laronda et al. 2017). Cells and tissue culture can benefit from using micro- and nano-fluidics technologies as well, as these allow configuration of different elaborated systems, which could integrate, automate and synchronize specific steps of the process, in accordance with the physiologic needs of the cells. As an illustration in our field, Xiao et al. (2017) have taken these technologies to the next step in exploring the tissue-tissue interactions in the context of female reproductive system (Xiao et al. 2017). They have integrated tissues from the female reproductive tract and peripheral organs (mouse ovary and human fallopian tube, ectocervix, liver) into a microfluidic culture system (Evatar) and successfully recapitulated the human 28-day menstrual cycle in vitro (Xiao et al. 2017). 


\section{The final step of an in vitro-grown follicle: inducing meiosis in vitro}

IVM has been successfully used in animal models, e.g. porcine (Hirao et al. 1994) and bovine (Van den Hurk et al. 2000, Hirao et al. 2013, Dieci et al. 2016), where large amounts of COCs can be obtained from small and mid-size antral follicles of slaughterhouse ovaries and maturation rates are relatively high (Pavlok et al. 1992, Merton et al. 2003). In these species, IVM has become the preferred method for livestock breeding, embryonic stem cell technologies, cloning and transgenic animal production. IVM was introduced by Trounson et al. (1994) as an assisted reproduction technique (ART) for women with PCOS because it reduces gonadotrophininduced ovarian hyperstimulation risk, but it could represent a valuable technique for fertility preservation, together with or as an alternative to follicle culture. Since its establishment as a clinical practice, IVM has been characterized by incongruent outcomes in part due to intrinsic low developmental competence of immature oocytes retrieved from small and mid-size antral follicles, in part attributed to the heterogeneity of protocols and technical approaches across fertility centers (Son \& Tan 2010). The IVM methodologies currently available target the cohort of follicles between 6 and $12 \mathrm{~mm}$, and most clinicians opt for injecting human chorionic gonadotropin (HCG) in order to improve COCs recovery rate and to obtain germinal vesicle (GV) oocytes of a sufficiently progressed developmental competence (Son et al. 2005). However, the diversity in follicle sizes present at the moment of HCG injection results in the retrieval of oocytes at diverse maturation stages, with consequent complications in fertilization procedures for the lab (Son et al. 2008, Son \& Tan 2010) and outcomes interpretation. Additionally, the HCG trigger may lead to increased apoptosis incidence in those follicles that have not yet a fully upregulated aromatase complex (Hillier 1993). Literature review on clinical IVM in PCOS patients concluded that implantation rates per COC retrieved from 10 to $12 \mathrm{~mm}$ follicles post-HCG trigger can vary from 5.5 to $34.5 \%$ (median $10.9 \%$ ) (Son \& Tan 2010). Therefore, due to the large variability in outcomes, constraints in the embryology laboratory and lower efficiency in ongoing pregnancy rates (OPRs) compared to IVF (Walls et al. 2015), IVM has not become a widely adopted ART. Nevertheless, a few IVF teams recognized that with modifications in the practice, IVM could have a future. A potential strategy for improving IVM applicability and outcomes consists in retrieving homogeneous pools of COCs at smaller diameters, to avoid being confronted with an excessive progression of inter-follicular selection (Gougeon 1986). In order to obtain COCs of an equal (GV) maturation stage for culture, is necessary to omit the HCG injection before oocyte retrieval (De Vos et al. 2011, Walls et al. 2015). This therapeutic choice preferentially leads to the retrieval of unexpanded COCs from follicles of significantly smaller diameters $(2-8 \mathrm{~mm})$. Sánchez et al. (2015) indicated that only half of the COCs retrieved under this condition have a condensed chromatin configuration (peri-nucleolar chromatin rim) and is transcriptionally silent, major features associated with acquisition of meiotic and developmental competencies in different animal species (Zuccotti et al. 2002, Lodde et al. 2007, Tan et al. 2009, Luciano et al. 2012, Labrecque et al. 2015). Consequently, maximally $50 \%$ of the retrieved oocytes from 2 to $8 \mathrm{~mm}$ follicles has the potential to extrude the first polar body (PB) after $30 \mathrm{~h}$ and yielded, with this protocol, $41 \%$ cumulative OPR per IVM cycle (unpublished results UZ Brussel). Comparable results were previously reported in a retrospective case-controlled study from Perth with a similar COC retrieval strategy in PCOS patients (Walls et al. 2015). Latter study also showed that the number of usable blastocysts formed in IVM was only $65 \%$ of what regular intracytoplasmic sperm injection (ICSI) obtained. The clinical data indicate that the major challenge within the IVM systems is to overcome the asynchrony in oocyte maturity (nuclear and cytoplasmic) of the COC from 2 to $8 \mathrm{~mm}$ follicles, before exposing them to a positive meiotic trigger. Indeed, removing oocytes from midsize antral follicles leads to a 'precocious' re-initiation of nuclear maturation, which disturbs the 'capacitation' process during which oocytes acquire the cytoplasmic machinery that supports preimplantation development (Hyttel et al. 1997, Dieleman et al. 2002, Gilchrist \& Thompson 2007). Hence, premature resumption of meiosis must be prohibited, while synchronization of nuclear and cytoplasmic maturation should be favored. In order to achieve this goal, a pre-maturation step during which meiotic arrest is imposed via modulation of the cyclic adenosine monophosphate (cAMP) signaling pathway has been introduced before the IVM culture in animal and human models. This approach was the base of the simulated physiological oocyte maturation (SPOM) system (Albuz et al. 2010). Applying the SPOM protocol, IVM was extended by $6 \mathrm{~h}$ in bovine and $4 \mathrm{~h}$ in mouse and COCs were firstly treated with 3-isobutyl1-methylxanthine (IBMX) during pre-maturation and then cultured in the presence of an oocyte-specific phosphodiesterase inhibitor, while simultaneously induced to mature with $\mathrm{FSH}$ to mimic oocyte maturation in vivo (Albuz et al. 2010). The combination of prematuration in the presence of IBMX and IVM culture increased blastocyst yield in bovine (Luciano et al. 1999, Albuz et al. 2010) and Day 3 human embryos generated from COCs exposed to IBMX during the collection phase preceding IVM, did not show increased incidence of chromosomal abnormalities compared with regular IVF embryos (Spits et al. 2015). However, maturation rate was nearly $50 \%$, as observed in the IVM systems without hCG trigger (UZ Brussel, unpublished data). In the same perspective, prior research made use 
of specific phosphodiesterase type 3 inhibitors (PDE3-I, cilostamide, Org 9935) to maintain human oocytes under temporary meiotic arrest in vitro and promote developmental competence (Nogueira et al. 2003, Shu et al. 2008, Vanhoutte et al. 2008, 2009). Observing the COC during the pre-maturation phase, it was concluded that the biggest challenges in pre-maturation setups were to maintain a functional connection between oocytes and cumulus cells and then to relieve the induced meiotic arrest by a positive meiotic stimulus, as is the case in vivo. The transzonal projections (TZPs) mediate the accumulation of transcripts and proteins into the ooplasm (Macaulay et al. 2014, 2016), which is crucial for oocyte competence acquisition (Gilchrist et al. 2008, Luciano et al. 2011, Lodde et al. 2013).

Abundant work in several animal models (Zhang et al. 2011, Franciosi et al. 2014, Wei et al. 2015, Zhang et al. 2015a,b, Zhong et al. 2016), inspired by initial work from the Eppig-Lab and the Conti-Lab, showed that CNP can be used during pre-maturation culture (PMC) to maintain immature oocytes under meiotic arrest. An overview of the main approaches taken to prevent meiosis resumption in GV oocytes during PMC culture is presented in Fig. 4. CNP is known as the natural oocyte maturation inhibitor present in the follicle (Zhang et al. 2010, Kawamura et al. 2011, Tsuji et al. 2012). A schematic representation of the mechanism of action of CNP in maintaining the meiotic arrest, compared with SPOM is showed in Fig. 5. Remarkably, a PMC combining CNP with E2, FSH and growth differentiation factor 9 (GDF9) enhanced maturation, developmental potential of low competence COCs obtained from unstimulated prepubertal mice, as evidenced by the improved blastocyst yield (Romero et al. 2016) and differently from cilostamide, preserved the integrity of TZPs (Fig. 6A and B). In a recent study involving sibling oocytes from a group of 15 infertile women with PCOS and addressed to prospectively evaluate the effects of a new IVM culture method on oocyte developmental competence, Sánchez et al. (2017) showed that PMC in the presence of CNP followed by IVM with FSH and amphiregulin (AREG) increases oocyte maturation potential compared to the clinical IVM protocol and leads to a higher availability of Day 3 embryos and good-quality blastocysts for single embryo transfer. Additionally, COCs preserved cumulus-oocyte connections after 24 or $46 \mathrm{~h}$ of PMC (Fig. 6C and D) and the blastocysts obtained after PMC + IVM did not show increased aneuploidy rates as compared to blastocysts from age-matched infertile patients from conventional ART (Sánchez et al. 2017).

In case a woman would need urgent chemotherapy or radiotherapy, which would put her fertility at risk, aspiration of the contents of the small $(2-8 \mathrm{~mm})$ or medium (9-12 mm) follicles present on default in the ovary, could provide valuable COC, without having to stimulate or operate her. In this perspective, improved

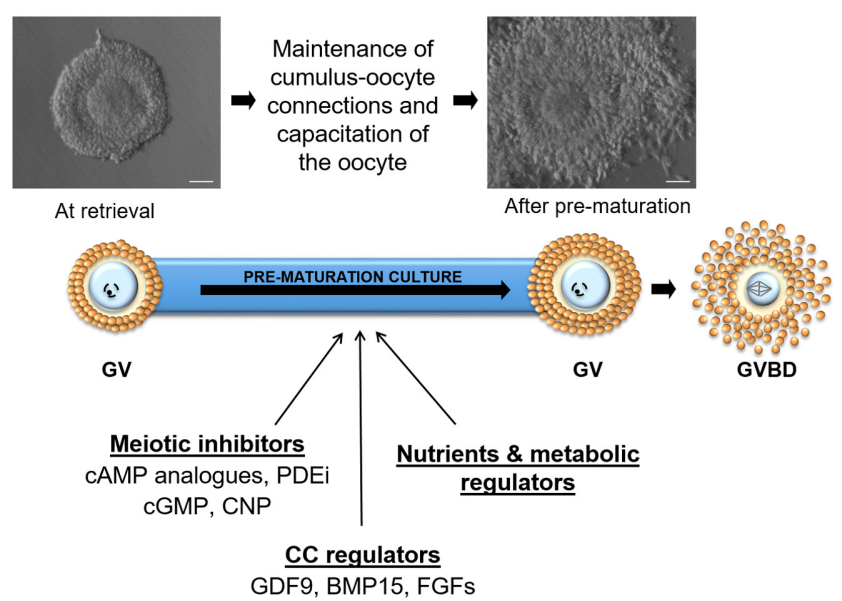

Figure 4 Capacitation of the oocyte and pre-maturation strategies. Not all the oocytes are competent to develop into embryos. Removal of the cumulus-oocyte-complex from the follicle results in spontaneous meiotic resumption with consequent induction of major asynchrony between nuclear and cytoplasmic maturation. A 'pre-maturation' culture strategy, with the aim to improve oocyte competence and in vitro maturation (IVM) efficiency, is illustrated here. Meiotic arrest can be achieved by using pharmacological agents during pre-maturation to provide oocytes with sufficient time to synchronize the maturation of the nucleus and cytoplasm. Making use of cAMP analogs or modifiers of PDEs and/or adenylate cyclase activity to delay or inhibit germinal vesicle break down, resulted in enhanced maturation potential and increased blastocyst The concept of oocyte 'capacitation' initially proposed by Hyttel et al. (1997) is indicating a potential that the oocyte should acquire during the growth phase and that includes modulations of organelles, ultrastructural modifications and transcription which allow the oocyte to attain meiotic and full developmental competence. This feature was not totally preserved by the pharmacological approach but it has been achieved by supplying CNP (Zhang et al. 2010), during the pre-maturation culture (Franciosi et al. 2014, Sánchez et al. 2017). The figure shows the image of a human COCs just after the pick-up and at the end of $24 \mathrm{~h}$ pre-maturation in presence of CNP. A functional communication between oocyte and somatic cells during the 'capacitation' period offers a window to intervene with different factors as cumulus cells regulators, OSFs (GDF9 and BMP15 in first option), nutrients and metabolites needed during later development, bridging in few hours a process that would otherwise require several days. BMP15, bone morphogenetic protein 15; cAMP, cyclic adenosine monophosphate; CGMP, cyclic guanosine monophosphate; CNP, C-type natriuretic peptide; FGFs, fibroblast growth factors; GDF9, growth differentiation factor 9; GV, germinal vesicle; GVBD, germinal vesicle break down; PDEi,

phosphodiesterase inhibitor.

IVM technologies may represent a valid alternative to follicle culture applications within IVF context. The proof of concept has already been provided (Segers et al. 2015). By further improving the understanding of gametogenesis and consequently selecting the most appropriate culture system per maturation stage/follicle size, the burden related with ART could realistically be shifted from treating the patient(s) to treating her gamete(s) into the clinical embryology lab (Fig. 7). 


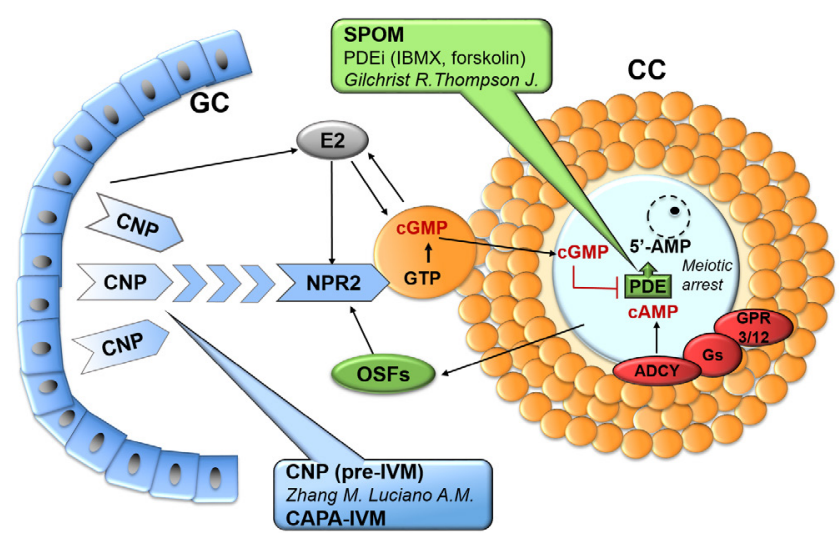

Figure 5 Overview of the main pathway involved in oocyte meiotic arrest (based on Zhang et al. 2010) and different strategies developed for the optimization of in vitro maturation. Cyclic nucleotides cAMP and cGMP are crucial to the maintenance of meiotic arrest. High levels of cAMP activate protein kinase A (PKA) (Bornslaeger et al. 1986) that, via downstream effectors, inhibits the protein complex CDK1/cyclin B (or meiosis-promoting factor, MPF), a positive regulator of meiotic progression (Jones 2004). Cyclic AMP in oocytes is generated downstream of GPR3 and GPR12, regulators of Gs proteins controlling adenylyl cyclase (ADCY) (Edwards 1965b, Mehlmann et al. 2004) while cGMP, originates in granulosa cells from the cumulus cell-specific guanylate cyclase NPR2 activity via CNP signaling. Before the LH-surge, cGMP is transferred via gap junctions to the oocyte where it inhibits PDE activity (Norris et al. 2009, Vaccari et al. 2009). E2, enhances CNP receptor signaling / coordinates NPR2 expression in cumulus cells and oocyte-secreted factors promote NPR2 mRNA accumulation in cumulus cells (Zhang et al. 2010). After the LH-surge PDE, an oocyte-specific

phosphodiesterase PDE3A, becomes activated to decrease cAMP levels in oocytes and initiates pathways governing meiotic resumption (Richard et al. 2001). When COCs are aspirated from the follicles, CNP signaling pathway is interrupted. Inability to sustain oocyte cAMP levels leads to precocious resumption of meiosis and loss of synchrony between oocyte maturation and ovulation. Therefore, the granulosa cell ligand CNP and its receptor NPR2 in cumulus cells prevent precocious meiotic maturation, which is critical for maturation and ovulation synchrony and for normal female fertility. First pre-IVM systems (Nogueira et al. 2003, Vanhoutte et al. 2008, 2009) invoked pharmacological control of meiosis arrest (PDE inhibitors, cilostamide, milnirone). In 2010, a novel in vitro SPOM system was proposed by Gilchrist's lab. This IVM system, as described by Albuz et al. (2010) entailed a pre-IVM phase of $1-2 \mathrm{~h}$ in presence of IBMX and forskolin to elevate COC/oocyte cAMP and an IVM phase containing a type-3 PDE inhibitor with simultaneous hormonal-induced oocyte maturation and extended IVM interval. ADCY, adenylyl cyclase; cAMP, cyclic adenosine monophosphate; CC, cumulus cells; cGMP, cyclic guanosine monophosphate; CNP, C-type natriuretic peptide; E2, estradiol; GC, granulosa cells; GPR 3/12, G-Protein-Coupled Receptor 3/12; Gs, G-proteins; GTP, Guanosine triphosphate; IBMX, 3-Isobutyl-1-methylxanthine; NPR2, natriuretic peptide receptor 2; OSFs, oocyte-secreted factors; PDE, phosphodiesterase; PDEi, phosphodiesterase inhibitor; SPOM, Simulated Physiological Oocyte Maturation.

\section{Conclusions}

In vitro follicle growth is an attractive strategy for fertility preservation as it does not require hormone stimulation of the patient, is suitable for both reproductive-age
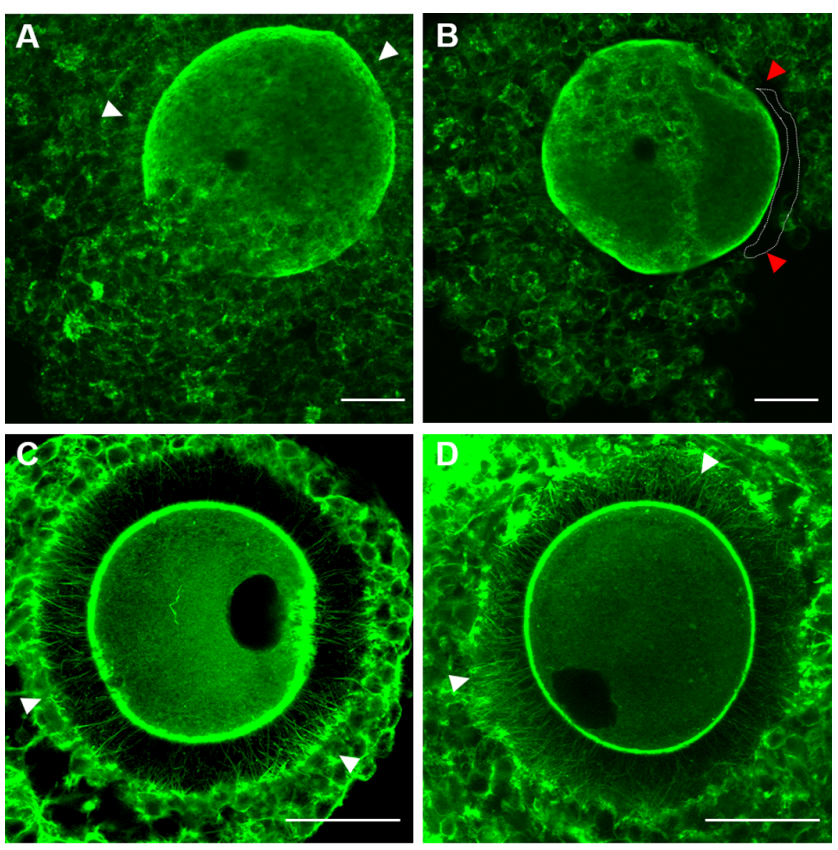

Figure 6 Immunofluorescent labeling of representative mouse (upper panel) and human (lower panel) cumulus oocyte complexes after pre-maturation culture. Cumulus-oocyte regulation is exerted via transzonal projections (TZPs), specialized extensions of cumulus cells and gap junctions, therefore the maintenance of TZPs integrity is a key factor for the acquisition of oocyte developmental competence (Albertini et al. 2001). F-actin staining (actin green) labels the cytoskeleton of cumulus cells and oocytes and allows the visualization of well-preserved TZPs at the oocyte-cumulus cell interface (A, C, D white arrows). Red arrows indicate the areas in which the contact between cumulus cells and oocyte is lost (B). In panels A (CNP, 48h) and B (cilostamide, 48h) two different approaches for keeping the meiotic arrest are compared in the mouse model. Differently from cilostamide, CNP preserves TZPs continuity around the oocyte (white arrows). Bottom panels depict surrounded human oocytes after $24 \mathrm{~h}(\mathrm{C})$ and $46 \mathrm{~h}$ (D) pre-maturation culture (PMC) in presence of CNP. Original magnification, mouse COCs (A, B) $\times 40$, zoom 2.0. Scale bar: $20 \mu \mathrm{m}$; human COCs (C, D) $\times 40$, zoom 2.5. Scale bar: $50 \mu \mathrm{m}$.

women and prepubertal girls and carries a very low risk of reintroducing cancer cells into the patient. The most successful follicle culture strategy to date in humans, which produced meiotically mature oocytes from in vitro-cultured follicles implies embedding preantral follicles in a matrix. In order to optimize the activation step of primordial follicles and after that the yield in meiotically competent oocytes from cultured tissue, a stage-dependent modulation of the matrix composition and the provision of stage-dependent biochemical growth factor supplementation will require more consideration. Access to recently characterized factors secreted by the oocyte in purified form, to purified ECM substances, which can be bioprinted, together with the assays for biomarkers which could indicate the culture needs throughout the long in vitro growth period, could improve quantity and quality in oocyte output. 


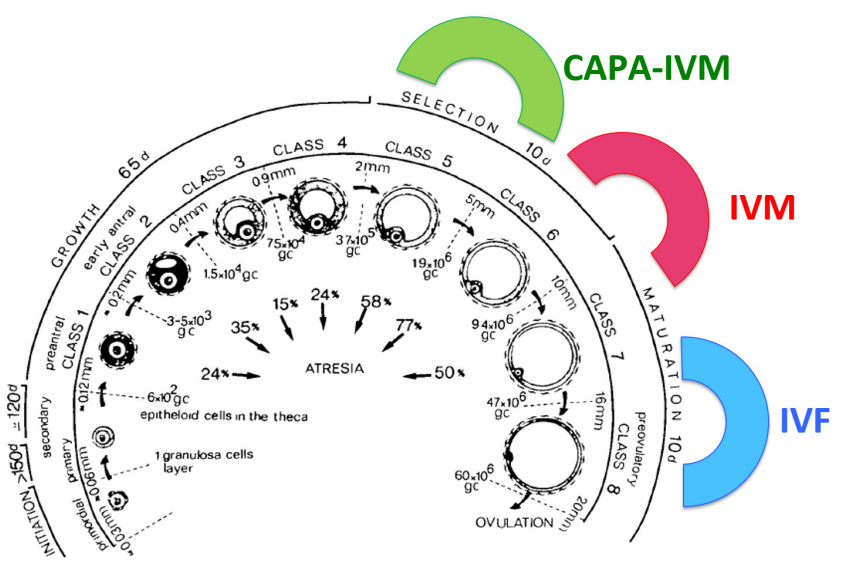

Figure 7 Selection of the proper culture system to support low competence oocytes deriving from small antral follicles based on the dynamic view of the follicle growth within the human ovary (modified from Gougeon (1986), permission asked, pending). By integrating 'morphometrical' and endocrinological data, as well as biological effects of different molecules synthesized by the human follicle, Gougeon proposed in 1986 a detailed model of follicle growth within the human ovary. Folliculogenesis starts when resting follicles enter the growth phase. Several months are required for a new growing follicle to reach the preantral stage $(0.15 \mathrm{~mm})$, then 70 additional days to reach the size of $2 \mathrm{~mm}$. Early growing follicle growth is regulated by interactions between $\mathrm{FSH}$ and local factors produced by theca, granulosa cells and oocyte. In the late luteal phase, follicles reaching $2 \mathrm{~mm}$ diameter, enter the selection stage and become sensitive to cyclic changes of FSH (Gougeon stage V). When compared to the entire oogenesis, maturation in vivo occurs in a very short temporal window, yet substantial processes as regulation of inhibition/induction of meiosis, physical and biochemical interaction with cumulus cells, chromatin condensation, organelle redistribution and cytoskeletal changes have to take place before the oocyte can reach full developmental competence in a follicle of minimally $17 \mathrm{~mm}$ diameter. Differently from IVF whose target are pre-ovulatory follicle(s) (>15 mm) which underwent already selection and in vivo maturation, IVM recruits oocytes from small antral follicles, just after the selection window. The oocyte is apparently able to recapitulate the same process in vitro, however some steps may occur abnormally, compromising oocyte quality/viability and maturation outcome. The majority of standard IVM systems target follicles between 6 and $12 \mathrm{~mm}$. CAPA IVM technology introduces a prematuration step that enables low developmental competence oocytes retrieved from follicles between 2 and $8 \mathrm{~mm}$ to develop into viable excellent quality blastocysts (Sánchez et al. 2017). The development of physiological culture systems able to support in a coordinated fashion the final development of oocytes according to follicles size, is mandatory to improve IVM outcomes and extend IVM clinical applicability.

Many advances have been made over the last 15 years in our understanding of the fundamental mechanisms regulating oocyte maturation in vivo and in vitro. Work from several researchers clarified that CNP and cGMP are responsible for CAMP-mediated meiotic arrest and how the ovulatory gonadotrophin surge reverses these processes. In the Graafian follicle in vivo, the transient surge in follicular somatic cell cAMP is important for subsequent oocyte developmental competence, as some IVM systems in routine would not recapitulate this cAMP surge in vitro, leading to the lower efficiency of IVM compared to clinical IVF. Next-generation IVM systems are in preclinical testing. These systems aim to (1) first prevent spontaneous meiotic resumption at oocyte collection using either phosphodiesterase inhibitors or CNP, subsequently (2) artificially increase the cAMP levels in COCs and/or finally (3) induce meiotic resumption using FSH, LH or EGF-like peptides. Such more sophisticated IVM systems typically lead to increased numbers of MII oocytes and to improvements of blastocyst yield. This research has implications for improving the efficacy and clinical uptake of clinical IVM and fertility preservation. Additional refinements of the culture conditions including, for instance, oocytesecreted factors (OSFs) or cytokines supplementation and appropriate scaffolds for 3D culture to replace the complex environment of the maturing oocyte, are expected to further improve current IVM outcomes. The coupling of small-follicle IVM technologies after tissue transplantation or in vitro growth (IVG) of follicle strategies might ultimately improve pregnancy outcomes for cancer patients. The IVM technology would also avoid the costly hormonal stimulation phase, by retrieving COCs from small antral follicles for in vitro culture. The technology would simplify treatment for infertile women and decrease considerably cost, risk and burden and would open access to treatment also in the less economical advanced regions of our world.

\section{Declaration of interest}

The authors declare that there is no conflict of interest that could be perceived as prejudicing the impartiality of this review.

\section{Funding}

IVM research at the Vrije Universiteit Brussel has been supported by grants from: The Institute for the Promotion of Innovation by Science and Technology in Flanders (Agentschap voor Innovatie door Wetenschap en TechnologieIWT, project 110680); the Fund for Research Flanders (Fonds Wetenschappelijk Onderzoek-Vlaanderen-FWO, project G.0343.13), the Belgian Foundation Against Cancer (Human Ovary Preservation Expertise (HOPE) project, Dossier C69).

\section{References}

Abir R, Fisch B, Fisher N, Samara N, Lerer-Serfaty G, Magen R, HermanEdelstein M, Ben-Haroush A, Stein A \& Orvieto R 2017 Attempts to improve human ovarian transplantation outcomes of needle-immersed vitrification and slow-freezing by host and graft treatments. Journal of Assisted Reproduction and Genetics 34 633-644. (https://doi. org/10.1007/s10815-017-0884-8)

Adhikari D \& Liu K 2009 Molecular mechanisms underlying the activation of mammalian primordial follicles. Endocrine Reviews 30 438-464. (https://doi.org/10.1210/er.2008-0048)

Adhikari D, Flohr G, Gorre N, Shen Y, Yang H, Lundin E, Lan Z, Gambello MJ \& Liu K 2009 Disruption of Tsc2 in oocytes leads to overactivation of the 
entire pool of primordial follicles. Molecular Human Reproduction 15 765-770. (https://doi.org/10.1093/molehr/gap092)

Adhikari D, Zheng W, Shen Y, Gorre N, Hamalainen T, Cooney AJ, Huhtaniemi I, Lan Z-J \& Liu K 2010 Tsc/mTORC1 signaling in oocytes governs the quiescence and activation of primordial follicles. Human Molecular Genetics 19 397-410. (https://doi.org/10.1093/hmg/ddp483)

Albertini DF, Combelles CM, Benecchi E \& Carabatsos MJ 2001 Cellular basis for paracrine regulation of ovarian follicle development. Reproduction 121 647-653. (https://doi.org/10.1530/rep.0.1210647)

Albuz FK, Sasseville M, Lane M, Armstrong DT, Thompson JG \& Gilchrist RB 2010 Simulated physiological oocyte maturation (SPOM): a novel in vitro maturation system that substantially improves embryo yield and pregnancy outcomes. Human Reproduction 25 2999-3011. (https://doi.org/10.1093/humrep/deq246)

Arunakumari G, Shanmugasundaram N \& Rao VH 2010 Development of morulae from the oocytes of cultured sheep preantral follicles. Theriogenology $\mathbf{7 4}$ 884-894. (https://doi.org/10.1016/j. theriogenology.2010.04.013)

Baba T, Ting AY, Tkachenko O, Xu J \& Stouffer RL 2017 Direct actions of androgen, estrogen and anti-Müllerian hormone on primate secondary follicle development in the absence of $\mathrm{FSH}$ in vitro. Human Reproduction 32 2456-2464. (https://doi.org/10.1093/humrep/dex322)

Bajaj P, Schweller RM, Khademhosseini A, West JL \& Bashir R 2014 3D biofabrication strategies for tissue engineering and regenerative medicine. Annual Review of Biomedical Engineering 16 247-276. (https://doi.org/10.1146/annurev-bioeng-071813-105155)

Bornslaeger EA, Poueymirou WT, Mattei P \& Schultz RM 1986 Effects of protein kinase $\mathrm{C}$ activators on germinal vesicle breakdown and polar body emission of mouse oocytes. Experimental Cell Research 165 507-17. (https://doi.org/10.1016/0014-4827(86)90603-8)

Cantley LC 2002 The phosphoinositide 3-kinase pathway. Science 296 1655-1657. (https://doi.org/10.1126/science.296.5573.1655)

Castrillon DH 2003 Suppression of ovarian follicle activation in mice by the transcription factor Foxo3a. Science 301 215-218. (https://doi. org/10.1126/science.1086336)

Chalhoub N \& Baker SJ 2009 PTEN and the PI3-kinase pathway in cancer. Annual Review of Pathology: Mechanisms of Disease 4 127-150. (https:// doi.org/10.1146/annurev.pathol.4.110807.092311)

Cheng Y, Kim J, Li XX \& Hsueh AJ 2015 Promotion of ovarian follicle growth following mTOR activation: synergistic effects of AKT stimulators. PLOS ONE 10 e0117769. (https://doi.org/10.1371/journal.pone.0117769)

Cortvrindt RG \& Smitz JE 2001 Fluorescent probes allow rapid and precise recording of follicle density and staging in human ovarian cortical biopsy samples. Fertility and Sterility 75 588-593. (https://doi.org/10.1016/ S0015-0282(00)01754-4)

De Vos M, Ortega-Hrepich C, Albuz FK, Guzman L, Polyzos NP, Smitz J \& Devroey P 2011 Clinical outcome of non-hCG-primed oocyte in vitro maturation treatment in patients with polycystic ovaries and polycystic ovary syndrome. Fertility and Sterility 96 860.e1-864.e1. (https://doi. org/10.1016/j.fertnstert.2011.07.1108)

De Vos M, Smitz J \& Woodruff TK 2014 Fertility preservation in women with cancer. The Lancet 384 1302-1310. (https://doi.org/10.1016/ S0140-6736(14)60834-5)

Derrar N, Price CA \& Sirard MA 2000 Effect of growth factors and coculture with ovarian medulla on the activation of primordial follicles in explants of bovine ovarian cortex. Theriogenology 54 587-598. (https:// doi.org/10.1016/S0093-691X(00)00374-5)

Dieci C, Lodde V, Labreque R, Dufort I, Tessaro I, Sirard M-A \& Luciano AM 2016 Differences in cumulus cell gene expression indicate the benefit of a pre-maturation step to improve in-vitro bovine embryo production. MHR: Basic Science of Reproductive Medicine 22 882-897. (https://doi. org/10.1093/molehr/gaw055)

Dieleman SJ, Hendriksen PJM, Viuff D, Thomsen PD, Hyttel P, Knijn HM, Wrenzycki C, Kruip TAM, Niemann H \& Gadella BM 2002 Effects of in vivo prematuration and in vivo final maturation on developmental capacity and quality of pre-implantation embryos. Theriogenology $\mathbf{5 7}$ 5-20. (https://doi.org/10.1016/S0093-691X(01)00655-0)

Dolmans M-M, Michaux N, Camboni A, Martinez-Madrid B, Van Langendonckt A, Annarita Nottola S \& Donnez J 2006 Evaluation of Liberase, a purified enzyme blend, for the isolation of human primordial and primary ovarian follicles. Human Reproduction 21 413-420. (https://doi.org/10.1093/humrep/dei320)
Dolmans M-M, Martinez-Madrid B, Gadisseux E, Guiot Y, Yuan WY, Torre A, Camboni A, Van Langendonckt A \& Donnez J 2007 Short-term transplantation of isolated human ovarian follicles and cortical tissue into nude mice. Reproduction 134 253-262. (https://doi.org/10.1530/ REP-07-0131)

Donnez J \& Dolmans M-M 2015 Ovarian cortex transplantation: 60 reported live births brings the success and worldwide expansion of the technique towards routine clinical practice. Journal of Assisted Reproduction and Genetics 32 1167-1170. (https://doi.org/10.1007/ s10815-015-0544-9)

Edwards RG 1965a Maturation in vitro of mouse, sheep, cow, pig, rhesus monkey and human ovarian oocytes. Nature 208 349. (https://doi. org/10.1038/208349a0)

Edwards RG 1965b Maturation in vitro of human ovarian oöcytes. Lancet 2 926-9. (https://doi.org/10.1016/S0140-6736(65)92903-X)

Eppig JJ \& O'Brien MJ 1996 Development in vitro of mouse oocytes from primordial follicles. Biology of Reproduction 54 197-207. (https://doi. org/10.1095/biolreprod54.1.197)

Faddy MJ \& Gosden RG 1996 A model conforming the decline in follicle numbers to the age of menopause in women. Human Reproduction 11 1484-1486. (https://doi.org/10.1093/oxfordjournals.humrep.a019422)

Franciosi F, Coticchio G, Lodde V, Tessaro I, Modina SC, Fadini R, Dal Canto M, Renzini MM, Albertini DF \& Luciano AM 2014 Natriuretic peptide precursor $C$ delays meiotic resumption and sustains gap junction-mediated communication in bovine cumulus-enclosed oocytes. Biology of Reproduction 91 61. (https://doi.org/10.1095/ biolreprod.114.118869)

Gilchrist RB \& Thompson JG 2007 Oocyte maturation: emerging concepts and technologies to improve developmental potential in vitro. Theriogenology 67 6-15. (https://doi.org/10.1016/j. theriogenology.2006.09.027)

Gilchrist RB, Lane M \& Thompson JG 2008 Oocyte-secreted factors: regulators of cumulus cell function and oocyte quality. Human Reproduction Update 14 159-177. (https://doi.org/10.1093/humupd/ dmm040)

Gilpin A \& Yang Y 2017 Decellularization strategies for regenerative medicine: from processing techniques to applications. BioMed Research International 2017 1-13. (https://doi.org/10.1155/2017/9831534)

Gougeon A 1986 Dynamics of follicular growth in the human: a model from preliminary results. Human Reproduction 1 81-87. (https://doi. org/10.1093/oxfordjournals.humrep.a136365)

Gupta PSP, Ramesh HS, Manjunatha BM, Nandi S \& Ravindra JP 2008 Production of buffalo embryos using oocytes from in vitro grown preantral follicles. Zygote 16 57-63. (https://doi.org/10.1017/ S096719940700442X)

Hikabe O, Hamazaki N, Nagamatsu G, Obata Y, Hirao Y, Hamada N, Shimamoto S, Imamura T, Nakashima K, Saitou M et al. 2016 Reconstitution in vitro of the entire cycle of the mouse female germ line. Nature 539 299. (https://doi.org/10.1038/nature20104)

Hillier SG 1993 Ovarian stimulation with recombinant gonadotrophins: $\mathrm{LH}$ as adjunct to FSH. In The New Frontier in Ovulation Induction, pp 39-47. Ed HS Jacobs. Carnforth: Parthenon.

Hirao Y, Nagai T, Kubo M, Miyano T, Miyake M \& Kato S 1994 In vitro growth and maturation of pig oocytes. Journal of Reproduction and Fertility 100 333-339. (https://doi.org/10.1530/jrf.0.1000333)

Hirao Y, Naruse K, Kaneda M, Somfai T, Iga K, Shimizu M, Akagi S, Cao F, Kono T, Nagai T et al. 2013 Production of fertile offspring from oocytes grown in vitro by nuclear transfer in cattle. Biology of Reproduction $\mathbf{8 9}$ 57. (https://doi.org/10.1095/biolreprod.113.109439)

Hirshfield AN 1991 Development of follicles in the mammalian ovary. International Review of Cytology 124 43-101. (https://doi.org/10.1016/ S0074-7696(08)61524-7)

Holbourn KP, Acharya KR \& Perbal B 2008 The CCN family of proteins: structure-function relationships. Trends in Biochemical Sciences 33 461-473. (https://doi.org/10.1016/j.tibs.2008.07.006)

Hornick JE, Duncan FE, Shea LD \& Woodruff TK 2012 Isolated primate primordial follicles require a rigid physical environment to survive and grow in vitro. Human Reproduction 27 1801-1810. (https://doi. org/10.1093/humrep/der468)

Hornick JE, Duncan FE, Shea LD \& Woodruff TK 2013 Multiple follicle culture supports primary follicle growth through paracrine-acting signals. Reproduction 145 19-32. (https://doi.org/10.1530/REP-12-0233) 
Hovatta O, Silye R, Abir R, Krausz T \& Winston RM 1997 Extracellular matrix improves survival of both stored and fresh human primordial and primary ovarian follicles in long-term culture. Human Reproduction 12 1032-1036. (https://doi.org/10.1093/humrep/12.5.1032)

Hovatta O, Wright C, Krausz T, Hardy K \& Winston RML 1999 Human primordial, primary and secondary ovarian follicles in long-term culture: effect of partial isolation. Human Reproduction 14 2519-2524. (https:// doi.org/10.1093/humrep/14.10.2519)

Hsueh AJW, Kawamura K, Cheng Y \& Fauser BCJM 2015 Intraovarian control of early folliculogenesis. Endocrine Reviews 36 1-24. (https:// doi.org/10.1210/er.2014-1020)

Hyttel P, Fair T, Callesen H \& Greve T 1997 Oocyte growth, capacitation and final maturation in cattle. Theriogenology 47 23-32. (https://doi. org/10.1016/S0093-691X(96)00336-6)

John GB, Gallardo TD, Shirley LJ \& Castrillon DH 2008 Foxo3 is a PI3Kdependent molecular switch controlling the initiation of oocyte growth Developmental Biology 321 197-204. (https://doi.org/10.1016/j. ydbio.2008.06.017)

Jones KT 2004 Turning it on and off: M-phase promoting factor during meiotic maturation and fertilization. Molecular Human Reproduction 10 1-5. (https://doi.org/10.1093/molehr/gah009)

Jung D, Xiong J, Ye M, Qin X, Li L, Cheng S, Luo M, Peng J, Dong J, Tang F et al. 2017 In vitro differentiation of human embryonic stem cells into ovarian follicle-like cells. Nature Communications 8 15680. (https://doi. org/10.1038/ncomms15680)

Kawamura K, Cheng Y, Kawamura N, Takae S, Okada A, Kawagoe Y, Mulders S, Terada Y \& Hsueh AJW 2011 Pre-ovulatory LH/hCG surge decreases C-type natriuretic peptide secretion by ovarian granulosa cells to promote meiotic resumption of pre-ovulatory oocytes. Human Reproduction 26 3094-3101. (https://doi.org/10.1093/humrep/ der282)

Kawamura K, Cheng Y, Suzuki N, Deguchi M, Sato Y, Takae S, Ho C-H, Kawamura N, Tamura M, Hashimoto S et al. 2013 Hippo signaling disruption and Akt stimulation of ovarian follicles for infertility treatment. PNAS 110 17474-17479. (https://doi.org/10.1073/pnas.1312830110)

Labrecque R, Lodde V, Dieci C, Tessaro I, Luciano AM \& Sirard MA 2015 Chromatin remodelling and histone mRNA accumulation in bovine germinal vesicle oocytes: chromatin configuration and oocyte mRNA content. Molecular Reproduction and Development 82 450-462. (https://doi.org/10.1002/mrd.22494)

Laplante M \& Sabatini DM 2012 mTOR signaling in growth control and disease. Cell 149 274-293. (https://doi.org/10.1016/j.cell.2012.03.017)

Laronda MM, Duncan FE, Hornick JE, Xu M, Pahnke JE, Whelan KA Shea LD \& Woodruff TK 2014 Alginate encapsulation supports the growth and differentiation of human primordial follicles within ovarian cortical tissue. Journal of Assisted Reproduction and Genetics 31 1013-1028. (https://doi.org/10.1007/s10815-014-0252-x)

Laronda MM, Jakus AE, Whelan KA, Wertheim JA, Shah RN \& Woodruff TK 2015 Initiation of puberty in mice following decellularized ovary transplant. Biomaterials 50 20-29. (https://doi.org/10.1016/j. biomaterials.2015.01.051)

Laronda MM, Rutz AL, Xiao S, Whelan KA, Duncan FE, Roth EW Woodruff TK \& Shah RN 2017 A bioprosthetic ovary created using 3D printed microporous scaffolds restores ovarian function in sterilized mice. Nature Communications 8 15261. (https://doi.org/10.1038/ ncomms15261)

Lass A, Silye R, Abrams DC, Krausz T, Hovatta O, Margara R \& Winston RM 1997 Follicular density in ovarian biopsy of infertile women: a novel method to assess ovarian reserve. Human Reproduction 12 1028-1031. (https://doi.org/10.1093/humrep/12.5.1028)

Li J, Kawamura K, Cheng Y, Liu S, Klein C, Liu S, Duan E-K \& Hsueh AJW 2010 Activation of dormant ovarian follicles to generate mature eggs. PNAS 107 10280-10284. (https://doi.org/10.1073/pnas.1001198107)

Lodde V, Modina S, Galbusera C, Franciosi F \& Luciano AM 2007 Largescale chromatin remodeling in germinal vesicle bovine oocytes: interplay with gap junction functionality and developmental competence. Molecular Reproduction and Development 74 740-749. (https://doi. org/10.1002/mrd.20639)

Lodde V, Franciosi F, Tessaro I, Modina SC \& Luciano AM 2013 Role of gap junction-mediated communications in regulating large-scale chromatin configuration remodeling and embryonic developmental competence acquisition in fully grown bovine oocyte. Journal of Assisted
Reproduction and Genetics 30 1219-1226. (https://doi.org/10.1007/ s10815-013-0061-7)

Luciano AM, Pocar P, Milanesi E, Modina S, Rieger D, Lauria A \& Gandolfi F 1999 Effect of different levels of intracellular CAMP on the in vitro maturation of cattle oocytes and their subsequent development following in vitro fertilization. Molecular Reproduction and Development $\mathbf{5 4}$ 86-91. (https://doi.org/10.1002/(SICI)1098-2795(199909)54:1<86::AIDMRD13>3.0.CO;2-C)

Luciano AM, Franciosi F, Modina SC \& Lodde V 2011 Gap junctionmediated communications regulate chromatin remodeling during bovine oocyte growth and differentiation through cAMP-dependent mechanism(s). Biology of Reproduction 85 1252-1259. (https://doi. org/10.1095/biolreprod.111.092858)

Luciano AM, Lodde V, Franciosi F, Tessaro I, Corbani D \& Modina S 2012 Large-scale chromatin morpho-functional changes during mammalian oocyte growth and differentiation. European Journal of Histochemistry 56 37. (https://doi.org/10.4081/ejh.2012.e37)

Macaulay AD, Gilbert I, Caballero J, Barreto R, Fournier E, Tossou P, Sirard M-A, Clarke HJ, Khandjian ÉW, Richard FJ et al. 2014 The gametic synapse: RNA transfer to the bovine oocyte. Biology of Reproduction 91 90. (https://doi.org/10.1095/biolreprod.114.119867)

Macaulay AD, Gilbert I, Scantland S, Fournier E, Ashkar F, Bastien A, Saadi HAS, Gagné D, Sirard M-A, Khandjian ÉW et al. 2016 Cumulus cell transcripts transit to the bovine oocyte in preparation for maturation. Biology of Reproduction 94 16. (https://doi.org/10.1095/ biolreprod.114.127571)

Magalhães DM, Duarte ABG, Araújo VR, Brito IR, Soares TG, Lima IMT, Lopes CP, Campello CC, Rodrigues APR \& Figueiredo JR 2011 In vitro production of a caprine embryo from a preantral follicle cultured in media supplemented with growth hormone. Theriogenology 75 182-188. (https://doi.org/10.1016/j.theriogenology.2010.08.004)

McLaughlin M, Kinnell HL, Anderson RA \& Telfer EE 2014 Inhibition of phosphatase and tensin homologue (PTEN) in human ovary in vitro results in increased activation of primordial follicles but compromises development of growing follicles. Molecular Human Reproduction 20 736-744. (https://doi.org/10.1093/molehr/gau037)

McLaughlin M, Albertini DF, Wallace WHB, Anderson RA \& Telfer EE 2018 Metaphase II oocytes from human unilaminar follicles grown in a multistep culture system. MHR: Basic Science of Reproductive Medicine 24 135-142. (https://doi.org/10.1093/molehr/gay002)

Mehlmann LM, Saeki Y, Tanaka S, Brennan TJ, Evsikov AV, Pendola FL, Knowles BB, Eppig JJ \& Jaffe LA 2004 The Gs-linked receptor GPR3 maintains meiotic arrest in mammalian oocytes. Science $\mathbf{3 0 6}$ 1947-1950. (https://doi.org/10.1126/science.1103974)

Merton JS, de Roos APW, Mullaart E, de Ruigh L, Kaal L, Vos PLAM \& Dieleman SJ 2003 Factors affecting oocyte quality and quantity in commercial application of embryo technologies in the cattle breeding industry. Theriogenology 59 651-674. (https://doi.org/10.1016/S0093691X(02)01246-3)

Morohaku K, Tanimoto R, Sasaki K, Kawahara-Miki R, Kono T, Hayashi K, Hirao Y \& Obata Y 2016 Complete in vitro generation of fertile oocytes from mouse primordial germ cells. PNAS 113 9021-9026. (https://doi. org/10.1073/pnas.1603817113)

Murphy SV \& Atala A 2014 3D bioprinting of tissues and organs. Nature Biotechnology 32 773. (https://doi.org/10.1038/nbt.2958)

Muruvi W \& Fortune JE 2009 Kit ligand-KIT interaction is required for follicle activation and mediates insulin-stimulated activation of bovine primordial follicles in vitro. Biology of Reproduction 81 200-200. (https://doi.org/10.1093/biolreprod/81.s1.200)

Muruvi W, Picton HM, Rodway RG \& Joyce IM 2005 In vitro growth of oocytes from primordial follicles isolated from frozen-thawed lamb ovaries. Theriogenology 64 1357-1370. (https://doi.org/10.1016/j. theriogenology.2005.02.010)

Nogueira D, Albano C, Adriaenssens T, Cortvrindt R, Bourgain C, Devroey P \& Smitz J 2003 Human oocytes reversibly arrested in prophase I by phosphodiesterase type 3 inhibitor in vitro. Biology of Reproduction 69 1042-1052. (https://doi.org/10.1095/biolreprod.103.015982)

Norris RP, Ratzan WJ, Freudzon M, Mehlmann LM, Krall J, Movsesian MA, Wang H, Ke H, Nikolaev VO \& Jaffe LA 2009 Cyclic GMP from the surrounding somatic cells regulates cyclic AMP and meiosis in the mouse oocyte. Development 136 1869-78. (https://doi.org/10.1242/ dev.035238) 
O'Brien MJ, Pendola JK \& Eppig JJ 2003 A revised protocol for in vitro development of mouse oocytes from primordial follicles dramatically improves their developmental competence. Biology of Reproduction 68 1682-1686. (https://doi.org/10.1095/biolreprod.102.013029)

Pan D 2007 Hippo signaling in organ size control. Genes and Development 21 886-897. (https://doi.org/10.1101/gad.1536007)

Pavlok A, Lucas-Hahn A \& Niemann H 1992 Fertilization and developmental competence of bovine oocytes derived from different categories of antral follicles. Molecular Reproduction and Development 31 63-67. (https:// doi.org/10.1002/mrd.1080310111)

Picton HM, Mkandla A, Salha O, Wynn P \& Gosden RG 1999 O-020. Initiation of human primordial follicle growth in vitro in ultrathin slices of ovarian cortex. Human Reproduction 14 11-11. (https://doi. org/10.1093/humrep/14.Suppl_3.11)

Reddy P, Shen L, Ren C, Boman K, Lundin E, Ottander U, Lindgren P, Liu Y, Sun Q \& Liu K 2005 Activation of Akt (PKB) and suppression of FKHRL1 in mouse and rat oocytes by stem cell factor during follicular activation and development. Developmental Biology 281 160-170. (https://doi. org/10.1016/j.ydbio.2005.02.013)

Reddy P, Liu L, Adhikari D, Jagarlamudi K, Rajareddy S, Shen Y, Du C, Tang W, Hämäläinen T, Peng SL et al. 2008 Oocyte-specific deletion of pten causes premature activation of the primordial follicle pool. Science 319 611-613. (https://doi.org/10.1126/science.1152257)

Reddy P, Adhikari D, Zheng W, Liang S, Hämäläinen T, Tohonen V, Ogawa W, Noda T, Volarevic S, Huhtaniemi I et al. 2009 PDK1 signaling in oocytes controls reproductive aging and lifespan by manipulating the survival of primordial follicles. Human Molecular Genetics 18 2813-2824. (https://doi.org/10.1093/hmg/ddp217)

Richard FJ, Tsafriri A \& Conti M 2001 Role of phosphodiesterase type 3A in rat oocyte maturation. Biology of Reproduction 65 1444-51. (https:// doi.org/10.1095/biolreprod65.5.1444)

Romero S, Sánchez F, Lolicato F, Van Ranst H \& Smitz J 2016 Immature oocytes from unprimed juvenile mice become a valuable source for embryo production when using C-type natriuretic peptide as essential component of culture medium. Biology of Reproduction 95 64-64. (https://doi.org/10.1095/biolreprod.116.139808)

Sánchez F \& Smitz J 2012 Molecular control of oogenesis. Biochimica et Biophysica Acta (BBA) - Molecular Basis of Disease 1822 1896-1912. (https://doi.org/10.1016/j.bbadis.2012.05.013)

Sánchez F, Romero S, Albuz FK \& Smitz J 2012 In vitro follicle growth under non-attachment conditions and decreased FSH levels reduces Lhcgr expression in cumulus cells and promotes oocyte developmental competence. Journal of Assisted Reproduction and Genetics 29 141-152. (https://doi.org/10.1007/s10815-011-9690-x)

Sánchez F, Romero S, De Vos M, Verheyen G \& Smitz J 2015 Human cumulus-enclosed germinal vesicle oocytes from early antral follicles reveal heterogeneous cellular and molecular features associated with in vitro maturation capacity. Human Reproduction 30 1396-1409. (https:// doi.org/10.1093/humrep/dev083)

Sánchez F, Lolicato F, Romero S, De Vos M, Van Ranst H, Verheyen G, Anckaert E \& Smitz JEJ 2017 An improved IVM method for cumulusoocyte complexes from small follicles in polycystic ovary syndrome patients enhances oocyte competence and embryo yield. Human Reproduction 32 2056-2068. (https://doi.org/10.1007/s10815-0119690-x)

Segers I, Mateizel I, Van Moer E, Smitz J, Tournaye H, Verheyen G \& De Vos M 2015 In vitro maturation (IVM) of oocytes recovered from ovariectomy specimens in the laboratory: a promising "ex vivo" method of oocyte cryopreservation resulting in the first report of an ongoing pregnancy in Europe. Journal of Assisted Reproduction and Genetics 32 1221-1231. (https://doi.org/10.1007/s10815-015-0528-9)

Shu Y-M, Zeng H-T, Ren Z, Zhuang G-L, Liang X-Y, Shen H-W, Yao S-Z, Ke P-Q \& Wang N-N 2008 Effects of cilostamide and forskolin on the meiotic resumption and embryonic development of immature human oocytes. Human Reproduction 23 504-513. (https://doi.org/10.1093/ humrep/dem344)

Silva JR, van den Hurk R, de Matos MH, dos Santos RR, Pessoa C, de Moraes MO \& de Figueiredo JR 2004 Influences of FSH and EGF on primordial follicles during in vitro culture of caprine ovarian cortical tissue. Theriogenology 61 1691-1704. (https://doi.org/10.1016/j. theriogenology.2003.09.014)
Silva GM, Rossetto R, Chaves RN, Duarte ABG, Araújo VR, Feltrin C, Bernuci MP, Anselmo-Franci JA, Xu M, Woodruff TK et al. 2015 In vitro development of secondary follicles from pre-pubertal and adult goats cultured in two-dimensional or three-dimensional systems. Zygote 23 475-484. (https://doi.org/10.1017/S0967199414000070)

Simpson L \& Parsons R 2001 PTEN: life as a tumor suppressor. Experimental Cell Research 264 29-41. (https://doi.org/10.1006/excr.2000.5130)

Smitz J, Dolmans MM, Donnez J, Fortune JE, Hovatta O, Jewgenow K, Picton HM, Plancha C, Shea LD, Stouffer RL et al. 2010 Current achievements and future research directions in ovarian tissue culture, in vitro follicle development and transplantation: implications for fertility preservation. Human Reproduction Update 16 395-414. (https://doi. org/10.1093/humupd/dmp056)

Son W-Y \& Tan SL 2010 Laboratory and embryological aspects of hCGprimed in vitro maturation cycles for patients with polycystic ovaries. Human Reproduction Update 16 675-689. (https://doi.org/10.1093/ humupd/dmq014)

Son W-Y, Lee S-Y \& Lim J-H 2005 Fertilization, cleavage and blastocyst development according to the maturation timing of oocytes in in vitro maturation cycles. Human Reproduction 20 3204-3207. (https://doi. org/10.1093/humrep/dei195)

Son W-Y, Chung J-T, Demirtas E, Holzer H, Sylvestre C, Buckett W, Chian RC \& Tan SL 2008 Comparison of in-vitro maturation cycles with and without in-vivo matured oocytes retrieved. Reproductive Biomedicine Online 17 59-67. (https://doi.org/10.1016/S1472-6483(10)60294-5)

Songsasen N, Woodruff TK \& Wildt DE 2011 In vitro growth and steroidogenesis of dog follicles are influenced by the physical and hormonal microenvironment. Reproduction 142 113-122. (https://doi. org/10.1530/REP-10-0442)

Spits C, Guzman L, Mertzanidou A, Jacobs K, Ortega-Hrepich C, Gilchrist RB, Thompson JG, De Vos M, Smitz J \& Sermon K 2015 Chromosome constitution of human embryos generated after in vitro maturation including 3-isobutyl-1-methylxanthine in the oocyte collection medium. Human Reproduction 30 653-663. (https://doi. org/10.1093/humrep/deu329)

Sun X, Su Y, He Y, Zhang J, Liu W, Zhang H, Hou Z, Liu J \& Li J 2015 New strategy for in vitro activation of primordial follicles with mTOR and PI3K stimulators. Cell Cycle 14 721-731. (https://doi.org/10.1080/15384101 .2014.995496)

Suzuki N, Yoshioka N, Takae S, Sugishita Y, Tamura M, Hashimoto S, Morimoto Y \& Kawamura K 2015 Successful fertility preservation following ovarian tissue vitrification in patients with primary ovarian insufficiency. Human Reproduction 30 608-615. (https://doi. org/10.1093/humrep/deu353)

Tagler D, Makanji Y, Tu T, Bernabé BP, Lee R, Zhu J, Kniazeva E, Hornick JE, Woodruff TK \& Shea LD 2014 Promoting extracellular matrix remodeling via ascorbic acid enhances the survival of primary ovarian follicles encapsulated in alginate hydrogels: ascorbic acid enhances survival. Biotechnology and Bioengineering 111 1417-1429. (https://doi.org/10.1002/bit.25181)

Tan J-H, Wang H-L, Sun X-S, Liu Y, Sui H-S \& Zhang J 2009 Chromatin configurations in the germinal vesicle of mammalian oocytes. Molecular Human Reproduction 15 1-9. (https://doi.org/10.1093/molehr/gan069)

Telfer EE \& Mclaughlin M 2012 Strategies to support human oocyte development in vitro. International Journal of Developmental Biology $\mathbf{5 6}$ 901-907. (https://doi.org/10.1387/ijdb.130001et)

Telfer EE \& Zelinski MB 2013 Ovarian follicle culture: advances and challenges for human and nonhuman primates. Fertility and Sterility 99 1523-1533. (https://doi.org/10.1016/j.fertnstert.2013.03.043)

Telfer EE, McLaughlin M, Ding C \& Thong KJ 2008 A two-step serum-free culture system supports development of human oocytes from primordial follicles in the presence of activin. Human Reproduction 23 1151-1158. (https://doi.org/10.1093/humrep/den070)

Ting AY, Xu J \& Stouffer RL 2015 Differential effects of estrogen and progesterone on development of primate secondary follicles in a steroiddepleted milieu in vitro. Human Reproduction 30 1907-1917. (https:// doi.org/10.1093/humrep/dev119)

Trounson A, Wood C \& Kausche A 1994 In vitro maturation and the fertilization and developmental competence of oocytes recovered from untreated polycystic ovarian patients. Fertility and Sterility 62 353-362. (https://doi.org/10.1016/S0015-0282(16)56891-5) 
Tsuji T, Kiyosu C, Akiyama K \& Kunieda T 2012 CNP/NPR2 signaling maintains oocyte meiotic arrest in early antral follicles and is suppressed by EGFR-mediated signaling in preovulatory follicles. Molecular Reproduction and Development 79 795-802. (https://doi.org/10.1002/ mrd.22114)

Vaccari S, Weeks I, James L, Hsieh M, Menniti FS \& Conti M 2009 Cyclic GMP signaling is involved in the luteinizing hormone-dependent meiotic maturation of mouse oocytes. Biology of Reproduction $\mathbf{8 1}$ 595-604. (https://doi.org/10.1095/biolreprod.109.077768)

Van den Hurk R, Abir R, Telfer EE \& Bevers MM 2000 Primate and bovine immature oocytes and follicles as sources of fertilizable oocytes. Human Reproduction Update 6 457-74. (https://doi.org/10.1093/ humupd/6.5.457)

Vanhoutte L, Nogueira D \& De Sutter P 2008 Prematuration of human denuded oocytes in a three-dimensional co-culture system: effects on meiosis progression and developmental competence. Human Reproduction 24 658-669. (https://doi.org/10.1093/humrep/den420)

Vanhoutte L, Nogueira D, Dumortier F \& De Sutter P 2009 Assessment of a new in vitro maturation system for mouse and human cumulus-enclosed oocytes: three-dimensional prematuration culture in the presence of a phosphodiesterase 3-inhibitor. Human Reproduction 24 1946-1959. (https://doi.org/10.1093/humrep/dep104)

Walls ML, Hunter T, Ryan JP, Keelan JA, Nathan E \& Hart RJ 2015 In vitro maturation as an alternative to standard in vitro fertilization for patients diagnosed with polycystic ovaries: a comparative analysis of fresh, frozen and cumulative cycle outcomes. Human Reproduction $\mathbf{3 0}$ 88-96. (https://doi.org/10.1093/humrep/deu248)

Wandji S-A, Sršeň V, Voss AK, Eppig JJ \& Fortune JE 1996 Initiation in vitro of growth of bovine primordial follicles. Biology of Reproduction 55 942-948. (https://doi.org/10.1095/biolreprod55.5.942)

Wandji SA, Srsen V, Nathanielsz PW, Eppig JJ \& Fortune JE 1997 Initiation of growth of baboon primordial follicles in vitro. Human Reproduction 12 1993-2001. (https://doi.org/10.1093/humrep/12.9.1993)

Wei Q, Zhou C, Yuan M, Miao Y, Zhao X \& Ma B 2015 Effect of C-type natriuretic peptide on maturation and developmental competence of immature mouse oocytes in vitro. Reproduction, Fertility and Development 29 319-324. (https://doi.org/10.1071/RD15160)

West ER, Shea LD \& Woodruff TK 2007 Engineering the follicle microenvironment. Seminars in Reproductive Medicine 25 287-299. (https://doi.org/10.1055/s-2007-980222)

Woodruff TK \& Shea LD 2011 A new hypothesis regarding ovarian follicle development: ovarian rigidity as a regulator of selection and health. Journal of Assisted Reproduction and Genetics 28 3-6. (https://doi. org/10.1007/s10815-010-9478-4)

Wu J, Carrell DT \& Wilcox AL 2001 Development of in vitro-matured oocytes from porcine preantral follicles following intracytoplasmic sperm injection. Biology of Reproduction 65 1579-1585. (https://doi. org/10.1095/biolreprod65.5.1579)

Xiao S, Zhang J, Romero MM, Smith KN, Shea LD \& Woodruff TK 2015 In vitro follicle growth supports human oocyte meiotic maturation. Scientific Reports 5 17323. (https://doi.org/10.1038/srep17323)

Xiao S, Coppeta JR, Rogers HB, Isenberg BC, Zhu J, Olalekan SA, McKinnon KE, Dokic D, Rashedi AS, Haisenleder DJ et al. 2017 A microfluidic culture model of the human reproductive tract and 28-day menstrual cycle. Nature Communications 8 14584. (https://doi. org/10.1038/ncomms14584)

Xu M, West E, Shea LD \& Woodruff TK 2006 Identification of a stagespecific permissive in vitro culture environment for follicle growth and oocyte development. Biology of Reproduction 75 916-923. (https://doi. org/10.1095/biolreprod.106.054833)

Xu M, Barrett SL, West-Farrell E, Kondapalli LA, Kiesewetter SE, Shea LD \& Woodruff TK 2009a In vitro grown human ovarian follicles from cancer patients support oocyte growth. Human Reproduction 24 2531-2540. (https://doi.org/10.1093/humrep/dep228)

Xu M, West-Farrell ER, Stouffer RL, Shea LD, Woodruff TK \& Zelinski MB $2009 \mathrm{~b}$ Encapsulated three-dimensional culture supports development of nonhuman primate secondary follicles. Biology of Reproduction $\mathbf{8 1}$ 587-594. (https://doi.org/10.1095/biolreprod.108.074732)

Xu J, Bernuci MP, Lawson MS, Yeoman RR, Fisher TE, Zelinski MB \& Stouffer RL 2010 Survival, growth, and maturation of secondary follicles from prepubertal, young, and older adult rhesus monkeys during encapsulated three-dimensional culture: effects of gonadotropins and insulin. Reproduction 140 685-697. (https://doi.org/10.1530/REP-100284)

Xu J, Lawson MS, Yeoman RR, Pau KY, Barrett SL, Zelinski MB \& Stouffer RL 2011a Secondary follicle growth and oocyte maturation during encapsulated three-dimensional culture in rhesus monkeys: effects of gonadotrophins, oxygen and fetuin. Human Reproduction $\mathbf{2 6}$ 1061-1072. (https://doi.org/10.1093/humrep/der049)

Xu M, Fazleabas AT, Shikanov A, Jackson E, Barrett SL, HirshfeldCytron J, Kiesewetter SE, Shea LD \& Woodruff TK $2011 b$ In vitro oocyte maturation and preantral follicle culture from the luteal-phase baboon ovary produce mature oocytes. Biology of Reproduction 84 689-697. (https://doi.org/10.1095/biolreprod.110.088674)

Xu J, Lawson MS, Yeoman RR, Molskness TA, Ting AY, Stouffer RL \& Zelinski MB 2013 Fibrin promotes development and function of macaque primary follicles during encapsulated three-dimensional culture. Human Reproduction 28 2187-2200. (https://doi.org/10.1093/humrep/det093)

Xu J, Xu F, Lawson MS, Tkachenko OY, Ting AY, Kahl CA, Park BS, Stouffer RR \& Bishop CV 2017 Anti-Müllerian hormone is a survival factor and promotes the growth of rhesus macaque preantral follicles during matrix-free culture. Biology of Reproduction 98 197-207. (https:// doi.org/10.1093/biolre/iox181)

Yin H, Kristensen SG, Jiang H, Rasmussen A \& Andersen CY 2016 Survival and growth of isolated pre-antral follicles from human ovarian medulla tissue during long-term 3D culture. Human Reproduction 31 1531-1539. (https://doi.org/10.1093/humrep/dew049)

Zhai J, Yao G, Dong F, Bu Z, Cheng Y, Sato Y, Hu L, Zhang Y, Wang J, Dai S et al. 2016 In vitro activation of follicles and fresh tissue autotransplantation in primary ovarian insufficiency patients. Journal of Clinical Endocrinology and Metabolism 101 4405-4412. (https://doi. org/10.1210/jc.2016-1589)

Zhang H \& Liu K 2015 Cellular and molecular regulation of the activation of mammalian primordial follicles: somatic cells initiate follicle activation in adulthood. Human Reproduction Update 21 779-786. (https://doi. org/10.1093/humupd/dmv037)

Zhang M, Su Y-Q, Sugiura K, Xia G \& Eppig JJ 2010 Granulosa cell ligand nppc and its receptor NPR2 maintain meiotic arrest in mouse oocytes. Science 330 366-369. (https://doi.org/10.1126/science.1193573)

Zhang M, Su Y-Q, Sugiura K, Wigglesworth K, Xia G \& Eppig JJ 2011 Estradiol promotes and maintains cumulus cell expression of natriuretic peptide receptor 2 (NPR2) and meiotic arrest in mouse oocytes in vitro. Endocrinology 152 4377-4385. (https://doi.org/10.1210/en.2011-1118)

Zhang H, Risal S, Gorre N, Busayavalasa K, Li X, Shen Y, Bosbach B, Brännström M \& Liu K 2014 Somatic cells initiate primordial follicle activation and govern the development of dormant oocytes in mice. Current Biology 24 2501-2508. (https://doi.org/10.1016/j. cub.2014.09.023)

Zhang W, Yang Y, Liu W, Chen Q, Wang H, Wang X, Zhang Y, Zhang M \& Xia G 2015a Brain natriuretic peptide and C-type natriuretic peptide maintain porcine oocyte meiotic arrest: BNP and CNP inhibit porcine oocyte maturation. Journal of Cellular Physiology 230 71-81. (https://doi. org/10.1002/jcp.24682)

Zhang J, Wei Q, Cai J, Zhao X \& Ma B 2015b Effect of C-type natriuretic peptide on maturation and developmental competence of goat oocytes matured in vitro. PLoS ONE 10 e0132318. (https://doi.org/10.1371/ journal.pone.0132318)

Zhong Y, Lin J, Liu X, Hou J, Zhang Y \& Zhao X 2016 C-Type natriuretic peptide maintains domestic cat oocytes in meiotic arrest. Reproduction, Fertility and Development 28 1553. (https://doi.org/10.1071/RD14425)

Zuccotti M, Ponce RH, Boiani M, Guizzardi S, Govoni P, Scandroglio R, Garagna S \& Redi CA 2002 The analysis of chromatin organisation allows selection of mouse antral oocytes competent for development to blastocyst. Zygote $\mathbf{1 0} 73-8$. (https://doi.org/10.1017/ S0967199402002101)

Received 3 April 2018

First decision 27 April 2018

Revised manuscript received 1 June 2018

Accepted 19 June 2018 